\title{
Time-resolved emission reductions for atmospheric chemistry modelling in Europe during the COVID-19 lockdowns
}

\author{
Marc Guevara $^{1}$, Oriol Jorba ${ }^{1}$, Albert Soret ${ }^{1}$, Hervé Petetin ${ }^{1}$, Dene Bowdalo ${ }^{1}$, Kim Serradell ${ }^{1}$, Carles Tena ${ }^{1}$, \\ Hugo Denier van der Gon ${ }^{2}$, Jeroen Kuenen ${ }^{2}$, Vincent-Henri Peuch ${ }^{3}$, and Carlos Pérez García-Pando ${ }^{1,4}$ \\ ${ }^{1}$ Barcelona Supercomputing Center, Barcelona, 08034, Spain \\ ${ }^{2}$ Department of Climate, Air and Sustainability, TNO, Utrecht, the Netherlands \\ ${ }^{3}$ European Centre for Medium-Range Weather Forecasts, Reading, UK \\ ${ }^{4}$ ICREA, Catalan Institution for Research and Advanced Studies, Barcelona, 08010, Spain
}

Correspondence: Marc Guevara (marc.guevara@bsc.es)

Received: 8 July 2020 - Discussion started: 22 July 2020

Revised: 7 November 2020 - Accepted: 1 December 2020 - Published: 20 January 2021

\begin{abstract}
We quantify the reductions in primary emissions due to the COVID-19 lockdowns in Europe. Our estimates are provided in the form of a dataset of reduction factors varying per country and day that will allow the modelling and identification of the associated impacts upon air quality. The country- and daily-resolved reduction factors are provided for each of the following source categories: energy industry (power plants), manufacturing industry, road traffic and aviation (landing and take-off cycle). We computed the reduction factors based on open-access and near-realtime measured activity data from a wide range of information sources. We also trained a machine learning model with meteorological data to derive weather-normalized electricity consumption reductions. The time period covered is from 21 February, when the first European localized lockdown was implemented in the region of Lombardy (Italy), until 26 April 2020. This period includes 5 weeks (23 March until 26 April) with the most severe and relatively unchanged restrictions upon mobility and socio-economic activities across Europe. The computed reduction factors were combined with the Copernicus Atmosphere Monitoring Service's European emission inventory using adjusted temporal emission profiles in order to derive time-resolved emission reductions per country and pollutant sector. During the most severe lockdown period, we estimate the average emission reductions to be $-33 \%$ for $\mathrm{NO}_{x},-8 \%$ for non-methane volatile organic compounds (NMVOCs), $-7 \%$ for $\mathrm{SO}_{x}$ and $-7 \%$ for $\mathrm{PM}_{2.5}$ at the EU-30 level (EU-28 plus Norway and Switzerland). For all pollutants more than $85 \%$ of the total reduc-
\end{abstract}

tion is attributable to road transport, except $\mathrm{SO}_{x}$. The reductions reached $-50 \%\left(\mathrm{NO}_{x}\right),-14 \%$ (NMVOCs), $-12 \%$ $\left(\mathrm{SO}_{x}\right)$ and $-15 \%\left(\mathrm{PM}_{2.5}\right)$ in countries where the lockdown restrictions were more severe such as Italy, France or Spain. To show the potential for air quality modelling, we simulated and evaluated $\mathrm{NO}_{2}$ concentration decreases in rural and urban background regions across Europe (Italy, Spain, France, Germany, United-Kingdom and Sweden). We found the lockdown measures to be responsible for $\mathrm{NO}_{2}$ reductions of up to $-58 \%$ at urban background locations (Madrid, Spain) and $-44 \%$ at rural background areas (France), with an average contribution of the traffic sector to total reductions of $86 \%$ and $93 \%$, respectively. A clear improvement of the modelled results was found when considering the emission reduction factors, especially in Madrid, Paris and London where the bias is reduced by more than $90 \%$. Future updates will include the extension of the COVID-19 lockdown period covered, the addition of other pollutant sectors potentially affected by the restrictions (commercial and residential combustion and shipping) and the evaluation of other air quality pollutants such as $\mathrm{O}_{3}$ and $\mathrm{PM}_{2.5}$. All the emission reduction factors are provided in the Supplement.

\section{Introduction}

Since the end of February 2020, most European countries have imposed lockdowns to combat the spread of the COVID-19 pandemic, forcing many industries, businesses 
and transport networks to either close down or drastically reduce their activity. Such a socioeconomic disruption, which is unprecedented in many ways, has resulted in a sudden drop of atmospheric anthropogenic emissions, including both criteria pollutants and greenhouse gases. The fall of pollutant levels across countries has been identified in multiple studies through the analysis of ground-based and satellite air quality observations (e.g. Bauwens et al., 2020; Collivignarelli et al., 2020; Petetin et al., 2020). While these studies have assessed changes in pollutant concentrations, further understanding of the lockdown impacts upon air quality and climate requires quantifying the reduction of primary emissions. Emissions and weather changes are entangled and looking at concentration changes only can be largely affected by specific weather conditions, especially considering that the past winter and spring 2020 were exceptionally hot in Europe (C3S, 2017).

Understanding and quantifying the impact of the COVID19 lockdowns upon European emissions and air quality is difficult due to the heterogeneous implementation of restrictions across different countries, including (i) different starting dates of the restrictions, (ii) diversity in the levels and type of restrictions, (iii) changes in time of the restriction levels, and (iv) different spontaneous response by individuals (e.g. voluntary decision to change the way of commuting). The chronology of the lockdowns is illustrated in Fig. 1, which shows stringency index trends computed by the Oxford COVID-19 Government Response Tracker (OxCGRT) for selected countries (Hale et al., 2020). The stringency index reports how the response of governments varied over several indicators (e.g. school closures, restrictions in movement, implementation of economic policies), becoming stronger or weaker over the course of the COVID-19 pandemic. The analysis of the stringency index trends is focussed on six European countries with different lockdown patterns for illustration (Italy, Spain, France, Germany, the United Kingdom and Sweden). As observed, Italy was the country where restrictions first started, followed by Spain and France, where national lockdowns were imposed on 14 and 17 March, respectively. In contrast to Italy, where the transition from low to high stringency levels was gradual, these two countries abruptly experienced severe restrictions on movements and commercial and industrial activities. A similar pattern is observed for Germany and the United Kingdom (UK), where national lockdowns were imposed on the 20 and 23 March, respectively. Sweden, on the other hand, was one of the few European countries where no national lockdowns were implemented and only national recommendations (e.g. relatively soft social distancing measures) were provided to citizens. This is clearly illustrated in the evolution of its stringency index, which remained lower than in the other countries during the whole period.

Considering all of the above, the quantification of emission changes due to the COVID-19 lockdown requires the use of reduction factors that are, at least (i) country-dependent, (ii) pollutant-sector-dependent and (iii) day-dependent for some sectors. Some studies focussing on the quantification of emission reductions are beginning to be published. Le Quéré et al. (2020) quantified the reduction in daily $\mathrm{CO}_{2}$ emissions during the COVID-19 lockdown from January 2020 to April 2020 over 69 countries, 50 US states and 30 Chinese provinces for a total of six sectors of the economy (i.e. energy industry, manufacturing industry, road transport, residential sector, public sector and aviation). The study, which calculates the emission reductions based on national activity data, was focussed on estimating the expected impact of the lockdowns upon the 2020 annual $\mathrm{CO}_{2}$ emissions and climate, but it did not include an analysis of emission cuts of criteria pollutants $\left(\mathrm{NO}_{x}, \mathrm{SO}_{x}, \mathrm{NMVOCs}, \mathrm{NH}_{3}, \mathrm{PM}_{10}\right.$ and $\left.\mathrm{PM}_{2.5}\right)$ or air pollution levels. More recently, Menut et al. (2020) developed an emission scenario for western Europe to quantify the impact of the lockdowns on air quality levels. Although focussing on criteria pollutants, the emission scenario was limited to March 2020 and was set up using only the Apple movement trends, which were used to derived emission reductions not only for road transport but also for other anthropogenic sources (i.e. manufacturing industry, non-road transport and residential-commercial combustion).

We present an open-source dataset of day-, sector- and country-dependent emission reduction factors for Europe associated with the COVID-19 lockdowns. These factors are designed to support both the quantification of European primary emission reductions and the associated impacts upon air quality. Our emission reduction factors are based on a bottom-up approach that considers a wide range of information sources, including open-access and near-real-time measured activity data, proxy indicators and other available reports. The resulting dataset covers from 21 February 2020, the beginning of localized lockdown in Italy (region of Lombardy), to 26 April 2020 and the following anthropogenic source categories: energy industry, manufacturing industry, road transport and aviation (landing and take-off cycle, LTO).

To assure easy adoption of the emission reduction factors, they are produced in a format consistent with the CAMSREG-AP emission inventory developed under the Copernicus Global and Regional emissions service (CAMS_81) (Kuenen et al., 2014; Granier et al., 2019), whose main objective is to provide gridded distributions of global and European emissions in direct support of the Copernicus Atmosphere Monitoring Service (CAMS) production chains (Marécal et al., 2015; Huijnen et al., 2019; Rémy et al., 2019). In the framework of CAMS, the CAMS-REG-AP emission inventory is currently used by several modelling services, mainly to provide short-term air quality forecasts, long-term air quality re-analysis or policy support products. To illustrate the potential application of our reduction factors, we also performed air quality simulations to quantify and evaluate the observed changes in $\mathrm{NO}_{2}$ concentrations across Europe. We considered three emission scenarios: (i) a first one with business-as-usual emissions using the default CAMS-REG-AP inventory, (ii) a second one considering 


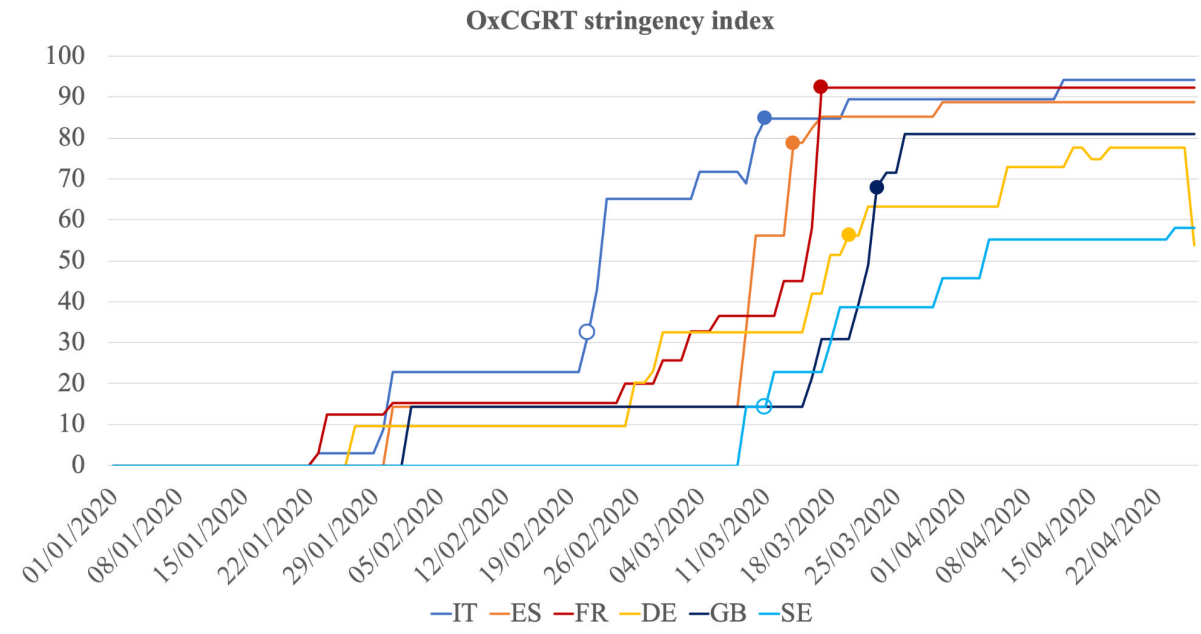

Figure 1. Evolution of the stringency index (0 to 100) computed by the Oxford COVID-19 Government Response Tracker (OxCGRT) (Hale et al., 2020) from 1 January to 26 April 2020 for selected countries (IT, Italy; ES, Spain; FR, France; DE, Germany; GB, United Kingdom; SE, Sweden). Filled circles indicate the starting dates of national lockdowns, and unfilled circles indicate the starting dates of the localized lockdown in Italy and national recommendations in Sweden.

only the traffic-related emission reductions and (iii) a third one including the reductions from all the aforementioned sectors. The difference between scenarios allows quantification of the impact of the lockdown measures on emissions and air quality levels and, particularly, the contribution of the road transport activity to the overall reductions. The study period of these modelling exercises covers 1 month prior to the first day of lockdown in Italy (20 January to 20 February) and more than 2 months of COVID-19 lockdown conditions (21 February to 26 April). Therefore, the focus of the work is on the transition to full lockdown conditions. The process toward normal conditions is still an ongoing process and will be assessed in future works.

Section 2 describes the methods and datasets used to estimate the European emission reduction factors for each one of the aforementioned pollutant sectors. Section 3 describes the setup of the modelling experiment to test the performance of the reduction factors on modelling the decrease in emissions and $\mathrm{NO}_{2}$ concentrations across Europe. Section 4 discusses the results obtained in terms of emissions and $\mathrm{NO}_{2}$ level reductions. Section 5 includes our main conclusions and perspectives for future updates.

\section{Time-, country- and sector-resolved emission reduction factors}

We computed a set of emission reduction factors for Europe that vary per day, country and sector. The resulting dataset follows the sector classification reported by the CAMSREG_AP emission inventory, which corresponds to the aggregated Gridded Nomenclature for Reporting (GNFR). We considered four GNFR sectors, GNFR_A (energy industry),
GNFR_B (manufacturing industry), GNFR_F (road transport) and GNFR_H (aviation), which we assumed to be the ones suffering the largest reduction in their activity during the COVID-19 lockdowns, in line with Le Quéré et al. (2020). Other sectors potentially affected by the COVID-19 lockdown such as GNFR_C (other stationary combustion activities) or GNFR_G (shipping) were not included in this first assessment and will be addressed in future releases of the dataset.

In terms of spatial coverage, we included as many countries as possible that are covered by the CAMS-REG_AP European working domain $\left(30^{\circ} \mathrm{W}-60^{\circ} \mathrm{E}\right.$ and $\left.30-72^{\circ} \mathrm{N}\right)(\mathrm{a}$ complete list of the countries can be found in Granier et al., 2019), giving special priority to EU-30 (EU-28 plus Norway and Switzerland). A list of the countries included for each sector is summarized in Table 2. The time span of the reduction factors is from 21 February to 26 April 2020. The beginning of the period corresponds to the date of the first localized lockdown in the region of Lombardy, Italy. Three distinct phases can be identified from the OxCGRT stringency index trends in Fig. 1: (i) a first phase without restrictions, with the exception of Italy (1 January to 12 March), (ii) a second phase with increasingly severe restrictions (12 to 23 March), and (iii) a third and final phase when the restrictions were at their maximum and remained almost unchanged for 5 weeks (23 March to 26 April).

We collected and processed daily measured time series representing the main activities of each sector. We then combined this information with specific methods in order to derive daily emission reduction factors as a function of the country and sector. Table 1 summarizes the main sources of information used and the countries included for each sector. 
Table 1. GNFR sector classification with the definition and sources of information used to derive emission reduction factors. The countries considered for each sector are also listed.

\begin{tabular}{|c|c|c|c|}
\hline Sector & Description & Sources of information & Countries included \\
\hline GNFR_A & Energy industry & $\begin{array}{l}\text { Electricity demand data: } \\
\text { ENTSO-E (2020); } \\
\text { FGC UES (2020) } \\
\text { Outdoor temperature: C3S } \\
\text { (2017) } \\
\text { Population map: CIESIN (2016) }\end{array}$ & $\begin{array}{l}\text { Austria, Belgium, Bulgaria, Croatia, Czech Republic, Estonia, } \\
\text { France, Germany, Greece, Hungary, Ireland, Italy, Latvia, Lithua- } \\
\text { nia, Netherlands, Poland, Portugal, Romania, Slovakia, Slovenia, } \\
\text { Spain, Sweden, Switzerland, the UK, Russia }\end{array}$ \\
\hline GNFR_B & $\begin{array}{l}\text { Manufacturing } \\
\text { industry }\end{array}$ & $\begin{array}{l}\text { Electricity demand data: } \\
\text { ENTSO-E (2020); } \\
\text { FGC UES (2020) } \\
\text { Outdoor temperature: C3S } \\
\text { (2017) } \\
\text { Population map: CIESIN (2016) } \\
\text { Energy balances: Eurostat } \\
\text { (2020a) }\end{array}$ & $\begin{array}{l}\text { Austria, Belgium, Bulgaria, Croatia, Czech Republic, Estonia, } \\
\text { France, Germany, Greece, Hungary, Ireland, Italy, Latvia, Lithua- } \\
\text { nia, Netherlands, Poland, Portugal, Romania, Slovakia, Slovenia, } \\
\text { Spain, Sweden, Switzerland, the UK, Russia }\end{array}$ \\
\hline GNFR_F & Road transport & $\begin{array}{l}\text { Movement trend reports: } \\
\text { Google }(2020)\end{array}$ & $\begin{array}{l}\text { Austria, Belgium, Bulgaria, Croatia, Republic of Cyprus, Czech } \\
\text { Republic, Denmark, Estonia, Finland, France, Germany, Greece, } \\
\text { Hungary, Ireland, Italy, Latvia, Lithuania, Luxembourg, Malta, } \\
\text { Netherlands, Poland, Portugal, Romania, Slovakia, Slovenia, } \\
\text { Spain, Sweden, Switzerland, the UK, Turkey, Georgia, Bosnia } \\
\text { and Herzegovina, Moldova, North Macedonia, Malta, Belarus }\end{array}$ \\
\hline GNFR_H & Aviation & $\begin{array}{l}\text { Airport movement statistics: } \\
\text { FlightRadar }(2020) \\
\text { Eurostat }(2020 \mathrm{~b})\end{array}$ & $\begin{array}{l}\text { Austria, Belgium, Bulgaria, Croatia, Republic of Cyprus, Czech } \\
\text { Republic, Denmark, Estonia, Finland, France, Germany, Greece, } \\
\text { Hungary, Ireland, Italy, Latvia, Lithuania, Luxembourg, Malta, } \\
\text { Netherlands, Poland, Portugal, Romania, Slovakia, Slovenia, } \\
\text { Spain, Sweden, Switzerland, the UK, North Macedonia, Norway }\end{array}$ \\
\hline
\end{tabular}

Table 2. Absolute $\left[\mu \mathrm{g} \mathrm{m}^{-3}\right.$ ] and relative changes [\%] of modelled $\mathrm{NO}_{2}$ concentrations at urban and rural background stations (UB, RB) for selected countries between 23 March and 26 April. The " $N$ " column indicates the number of stations used to compute the changes.

\begin{tabular}{llrrrrr}
\hline Country & $\begin{array}{l}\text { Station } \\
\text { type }\end{array}$ & $N$ & $\begin{array}{r}\text { covid19_traffic }- \\
\text { baseline (abs) }\end{array}$ & $\begin{array}{r}\text { covid19_all - } \\
\text { baseline (abs) }\end{array}$ & $\begin{array}{r}\text { covid19_traffic - } \\
\text { baseline (rel) }\end{array}$ & $\begin{array}{c}\text { covid19_all - } \\
\text { baseline (rel) }\end{array}$ \\
\hline IT (Milan) & UB & 6 & -17.1 & -17.7 & $-54 \%$ & $-56 \%$ \\
ES (Madrid) & UB & 19 & -13.1 & -14.9 & $-51 \%$ & $-58 \%$ \\
FR (Paris) & UB & 16 & -8.5 & -11.0 & $-32 \%$ & $-41 \%$ \\
DE (Berlin) & UB & 6 & -2.9 & -3.9 & $-23 \%$ & $-30 \%$ \\
GB (London) & UB & 8 & -7.4 & -8.3 & $-25 \%$ & $-28 \%$ \\
SE (all) & UB & 8 & -0.9 & -1.1 & $-10 \%$ & $-11 \%$ \\
IT & RB & 69 & -2.6 & -2.7 & $-41 \%$ & $-43 \%$ \\
ES & RB & 58 & -0.7 & -0.8 & $-28 \%$ & $-31 \%$ \\
FR & RB & 23 & -2.2 & -2.3 & $-42 \%$ & $-44 \%$ \\
DE & RB & 74 & -1.9 & -2.0 & $-26 \%$ & $-28 \%$ \\
GB & RB & 14 & -3.7 & -4.0 & $-28 \%$ & $-30 \%$ \\
SE & RB & 1 & -0.5 & -0.6 & $-11 \%$ & $-12 \%$ \\
\hline
\end{tabular}

The following subsections describe the data and methods for each sector along with the underlying assumptions.

\subsection{Energy industry}

We assumed the changes in emissions from the energy industry (which includes power and heat plants) to follow the changes observed in the electricity demand data reported by the European Network of Transmission System Operators 
for Electricity (ENTSO-E) transparency platform (Hirth et al., 2018; ENTSO-E, 2020). ENTSO-E centralizes the collection and publication of the electricity generation for each European member state. For each country, we collected daily electricity demand data for the years 2015 to 2020 (January to April). Data gaps and inconsistencies found in the original dataset were corrected using the electricity generation statistics reported by the national transmission system operators (TSOs). For Russia, we derived the electricity demand data directly from Russia's Federal Grid Company of Unified Energy System (FGC UES, 2020).

In addition to its characteristic weekly variability, with higher values during weekdays, part of the electricity demand is driven by temperature fluctuations. Therefore, to calculate the reduction in electricity demand during the COVID-19 lockdowns, we first estimated the business-as-usual (BAU) electricity demand, i.e. the demand that would have occurred in the absence of lockdowns under the same meteorological conditions. To estimate the BAU electricity demand we used machine learning models trained with meteorological data and other time features. This approach has been used to weather-normalize $\mathrm{NO}_{2}$ surface concentration time series, whose variability is also partly driven by the meteorological conditions, to quantify actual reductions of $\mathrm{NO}_{2}$ during the COVID-19 lockdown (Petetin et al., 2020). More specifically, we used gradient boosting machine (GBM) models trained and tuned independently for each country using daily data from January to April between 2015 and 2019. As inputs, we considered the following features: daily countrylevel population-weighted heating degree days (HDDs), date index (number of days since 1 January 2015), Julian date, day of week and a Boolean feature indicating the countryspecific bank holidays. The HDD is defined relative to a threshold temperature $\left(T_{\mathrm{b}}\right)$ above which a building needs no heating and is used to approximate the daily energy demand for heating a building (Quayle and Diaz, 1980). In order to provide a more realistic estimate of the potential electricity demand for space heating on a national level, we computed country-specific population-weighted HDD values $\left(\operatorname{HDD} \_p o p(d)\right)$ following Eq. (1):

$$
\operatorname{HDD} \_p o p(d)=\sum_{x=1}^{n} \frac{\left(\max \left(T_{\mathrm{b}}-T_{2 \mathrm{~m}}(x, d), 0\right)\right) \times \operatorname{Pop}(x)}{\sum_{x=1}^{n} \operatorname{Pop}(x)},
$$

where $T_{2 \mathrm{~m}}(x, d)$ is the daily mean $2 \mathrm{~m}$ outdoor temperature for grid cell $x$ and day $d\left[{ }^{\circ} \mathrm{C}\right], \operatorname{Pop}(x)$ is the amount of population included in grid cell $x$ [no. of inhabitants] and $n$ is the total number of grid cells that corresponds to a specific country. A threshold temperature value of $15.5^{\circ} \mathrm{C}$ was selected following Spinoni et al. (2015). Outdoor temperature information was obtained from the ERA5 reanalysis dataset for the period 2015-2020 (C3S, 2017), while information on gridded population was derived from the Gridded Population of the World, Version 4 (GPWv4; CIESIN, 2016).
Each grid cell was assigned to a specific country following the global country mask available in the Emissions of atmospheric Compounds and Compilation of Ancillary Data system (ECCAD, https://eccad.aeris-data.fr/, last access: January 2021).

Julian day and day of week serve here as proxies for the (climatological) main drivers of the seasonal and weekly variability of the power demand, and the date index acts as the trend term. We replicated the tuning strategy previously used in Petetin et al. (2020) with a random search in the hyper-parameter space and rolling-origin cross-validation (appropriate for time series). While the training and tuning of the GBM models were performed from 2015 to 2019, we used the first 2 months of 2020 (January-February) to test the performance of the models.

Figure 2 summarizes the main statistics (normalized mean bias, NMB; normalized root-mean-square error, NRMSE; and correlation, $r$ ) obtained from the comparison between measured and ML-based electricity demand during the first 2 months of 2020 for selected countries. Generally, a high correlation (above 0.9) and low NMB and NRMSE (below $5 \%$ ) are observed for all cases, especially in those countries with stronger lockdown restrictions such as Italy, France or Spain. In this study, ML models are used for predicting the fluctuations of electricity demand based on the temperature (and additional time features), assuming that temperature is a strong driver of electricity demand (for heating and air conditioning). However, temperature is obviously not the only driver of electricity demand variability that can be influenced by various other factors (e.g. change of technology, behaviour, regulation). In addition, the GBM models used in this study are non-parametric, meaning that they cannot extrapolate, i.e. predict electricity demand values outside the range of values used during the training phase. As a consequence, such models may perform poorly when an overly strong trend and/or inter-annual variability (not directly due to temperature variability) are affecting the electricity demand to predict. In practise, the results obtained in this study show that this approach performs relatively well in most countries, although there are some exceptions. The poorest performance was obtained in Finland $(r=0.33)$, due to a strong negative anomaly ( $-12 \%$ on average) of electricity demand in January-February 2020 compared to previous years used for training. As shown in Fig. S1 in the Supplement, the electricity demand reported by ENTSO-E for this country in early 2020 (i.e. late January-early February) was substantially lower than during all previous years (2015-2019). However, this anomaly in the power data cannot be explained by a drastic change in the temperature, as this parameter remained within the same range of values as during previous years. In such a situation, where changes in power demand cannot be related to changes in temperature, the ML cannot produce accurate predictions. Compared to most other countries, a larger NRMSE and lower correlation were also found in Luxembourg. In this case, we attribute the 


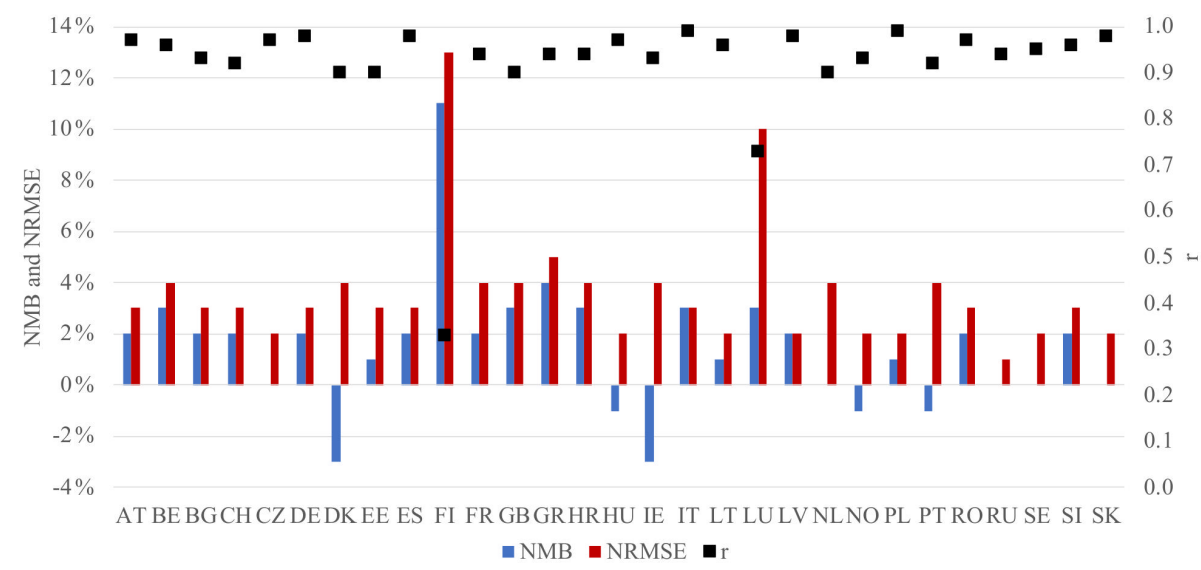

Figure 2. Summary of the statistics (normalized mean bias, NMB; normalized root-mean-square error, NRMSE; and correlation, $r$ ) obtained from the comparison between measured and computed electricity demand during the first 2 months of 2020 for selected countries.

low performance of the ML algorithm to the large data gap found in the historical data used for training. For instance, for the year 2019 the ENTSO-E dataset presents a temporal coverage lower than $50 \%$. In addition, despite relatively good statistics in early 2020, the electricity demand computed in Denmark and Norway shows a substantial and unexpected increase during the COVID-19 lockdown (up to $+12 \%$ ). In the case of Denmark, we found higher-than-usual electricity demand levels reported by ENTSO-E in late Februaryearly March 2020 which, as in the case of Finland, could not be directly explained by drastic changes in temperature (Fig. S2). At this time of the year, such relatively high-power demand was already observed in 2018 but because of strong cold waves, while temperature was not particularly cold in 2020. Like in the case of Finland, unexplained changes in the electricity demand induce errors in the predictive ML algorithm. For Norway, although the mean bias on the entire test period is relatively low, a closer look at the time series indicates that this bias was low at the beginning of the period and started to increase in mid-February and persisted during the lockdown (Fig. S3). Therefore, it is unclear to which extent the increase in electricity demand during the lockdown is real or simply the persistence of the bias previously observed before the lockdown starts (as both are of the same order of magnitude). Without additional sources of information and given the relatively soft mobility restrictions imposed in Norway, we also discarded the use of ML for this country and assumed that electricity demand during the lockdown period was not significantly impacted.

Considering all of the above, and as a precautionary measure, we assumed a null reduction of the electricity demand in Denmark, Finland and Norway and a fixed $-16 \%$ reduction in Luxembourg starting the first day of the national lockdown implementation (15 March), following the results reported by Le Quéré et al. (2020). Importantly, we do not expect that assuming a null reduction will cause a significant impact on the computed emission reductions, as the majority of the electricity production in these countries comes from renewable energy sources. For instance, in the case of Norway more than $90 \%$ of the electricity production comes from hydropower (IEA, 2020a)

The electricity demand started to decrease by the end of February and the beginning of March 2020 compared to the BAU electricity demand estimated from the GBM models in countries where strong restrictions had been implemented. We attributed these discrepancies to the direct effect of lockdown measures, regardless of the meteorological conditions, and used them to derive quantitative daily emission reduction factors for the energy industry sector (Eq. 2):

$$
\begin{aligned}
& \operatorname{RF}_{\text {ener_indu }}(d, c) \\
& =\left(\frac{\operatorname{ED}_{\text {COVID-19 }}(d, c)-\operatorname{ED}_{\text {measured }}(d, c)}{\operatorname{ED}_{\text {measured }}(d, c)}\right) \times 100,
\end{aligned}
$$

where $\mathrm{RF}_{\text {ener_indu }}(d, c)$ is the final reduction factor for the energy industry sector for day $d$ and country $c$ [\%], $\operatorname{ED}_{\text {COVID-19 }}(d, c)$ is the estimated BAU electricity demand computed using ML for day $d$ and country $c$ [MW], and $\operatorname{ED}_{\text {measured }}(d, c)$ is the measured electricity demand for day $d$ and country $c$ [MW].

Figure 3a illustrates the reduction factor trends obtained for selected countries. As expected, the strong weekly cycle of electricity demand normally observed in most countries smoothed down during the COVID-19 lockdown. The resulting trends are consistent with the national lockdown calendars and restriction levels implemented in each country. Italy is the first country where traffic activity reductions happened, followed by Spain, France, Germany, the UK and Sweden. This is in line with the starting dates of lockdown restrictions in each country (Sect. 2). For Spain, reduction increased between 30 March and 9 April, the most restrictive phase of the Spanish lockdown when only essential activities including food trade, pharmacy and some industries were authorized. In the case of Sweden, positive values are observed 
(a)

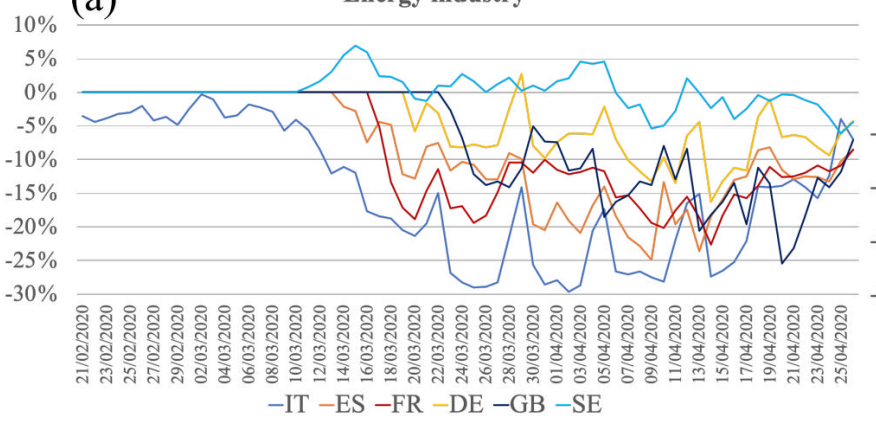

(c)

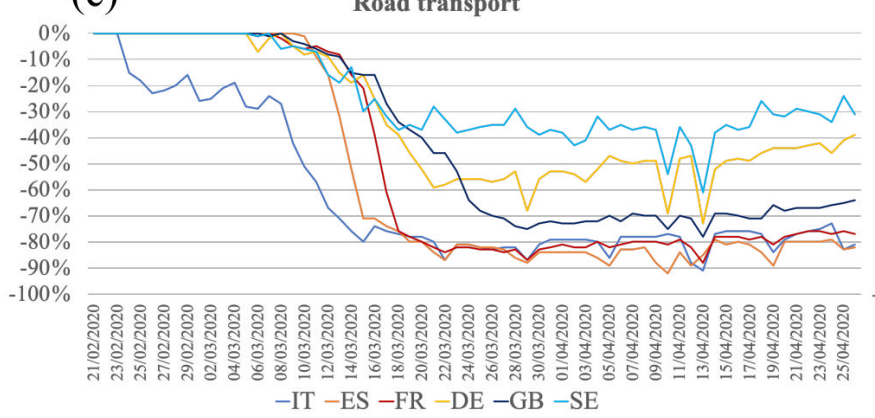

(b)

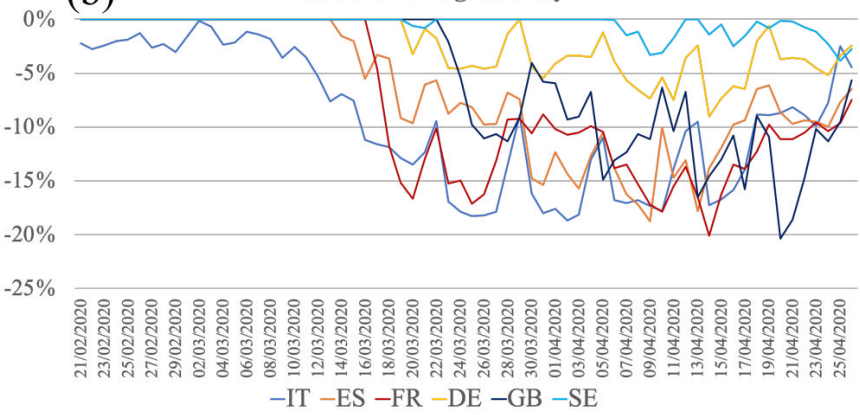

(d)

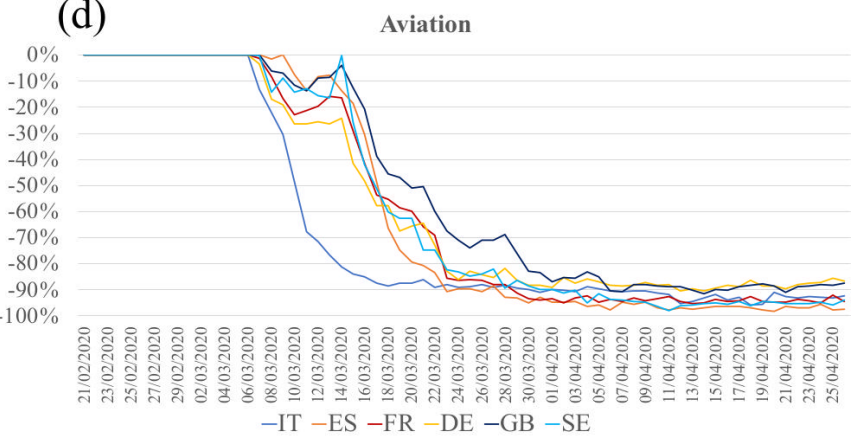

(e)

Daily temporal factors (road transport)

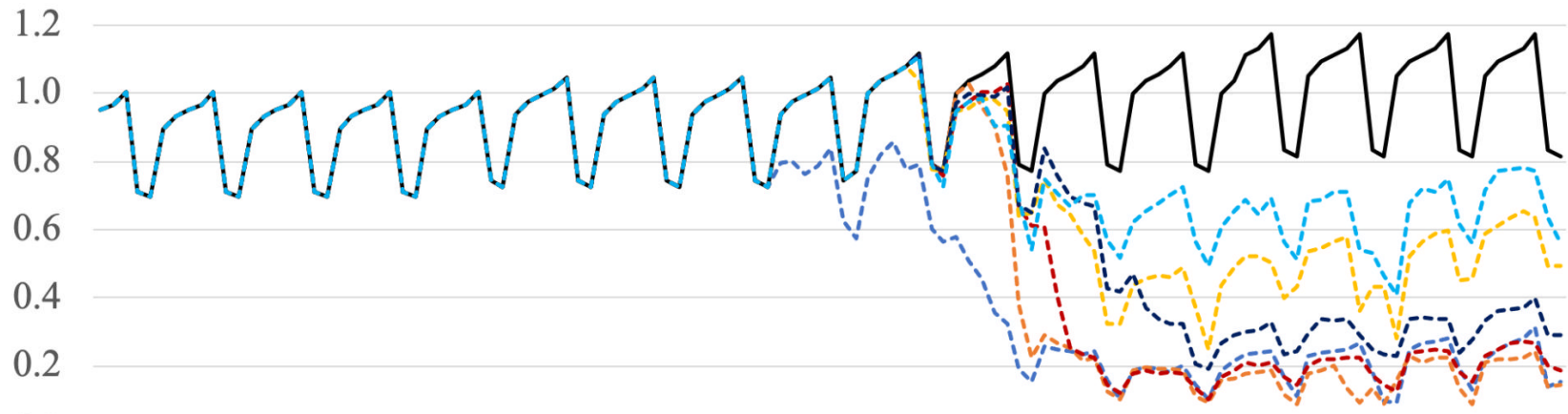

0.0

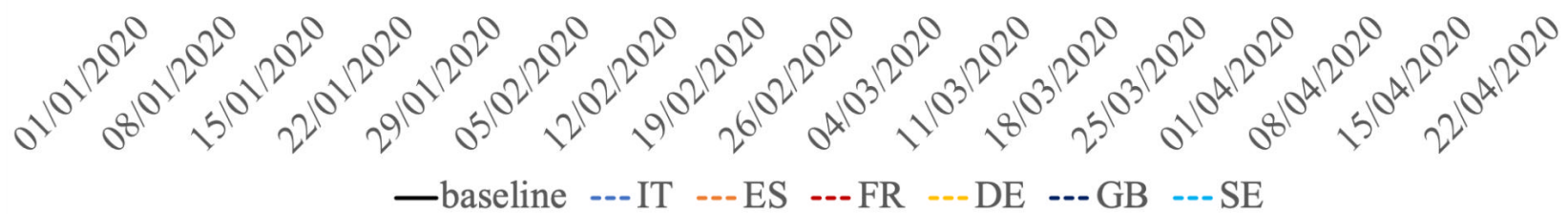

Figure 3. Emission reduction factors computed for the energy (a) and manufacturing (b) industries, road transport (c), and aviation (d) for selected countries (IT, Italy; ES, Spain; FR, France; DE, Germany; GB, Great Britain; SE, Sweden) for the period 21 February to 26 April 2020. Original and COVID-19 version of the emission daily temporal factors computed for the road transport sector and used for emission modelling (e).

for certain days until the beginning of April. These results agree with the ones reported in Le Quéré et al. (2020), who obtained a $4 \%$ increase during the lockdown for this country. It is likely that electricity demand from public and commercial services remained unperturbed as, in contrast to most countries, there was no enforced lockdown in Sweden. We also hypothesize that a voluntary self-isolation of a fraction of the population may have increased household electricity consumption. During the strictest period of the COVID-19 lockdown (23 March-26 April), Italy was the country experiencing the largest reductions $(-21 \%)$, followed by Spain $(-15 \%)$ and France $(-14.4 \%)$.

The countries for which daily reduction factors could be computed are shown in Table 1. For countries with no data, 
(a)

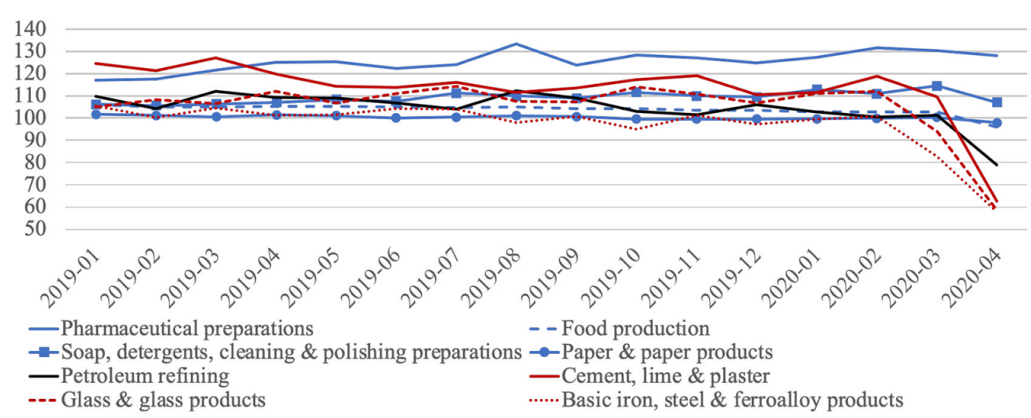

(b)

Electricity consumption in commercial/public services (Spain)

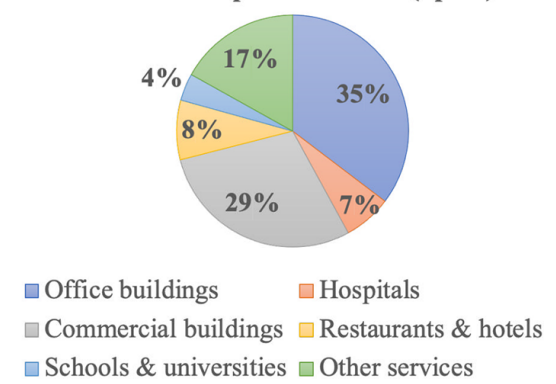

Figure 4. Evolution of the industrial production index in Spain for selected manufacturing industrial branches between January 2019 and April 2020 (INE, 2020) (a). Contribution of each commercial and public service branch to total electricity consumption in Spain for 2017 (IDAE, 2018) (b).

we constructed a set of reduction factors based on the average data of all the available countries except Italy, where the lockdown restrictions began approximately $3+$ weeks before other countries.

\subsection{Manufacturing industry}

The reduction factors for manufacturing industry are based on the daily electricity demand reduction factors described in Sect. 2.1. We attributed $25 \%$ of the total electricity demand reduction to the reduction in manufacturing industry activity, which is consistent with the $-27 \%$ decrease in electricity use by the manufacturing sector reported by the electricity transmission system operator of France (RTE, 2020). We estimated this value considering that (i) the European industry sector consumes $22.3 \%$ of the total final electricity demand (Eurostat, 2020a) and (ii) most of the electricity reduction during the lockdown can be linked to commercial and public services. Indeed, those industrial branches responsible for manufacturing essential goods (e.g. food, pharmaceutical preparations and other chemical products) remained almost unaffected during the COVID-19 lockdowns, in contrast to the commercial and public services sectors, which were forced to drastically reduce or even completely halt their activities (i.e. restaurants and hotels, office buildings, shopping centres). This fact is illustrated in Fig. 4 which shows, on the one hand, the evolution of the industrial production index (IPI) for selected industrial branches in Spain between January 2019 and April 2020 (INE, 2020) and, on the other hand, the contribution of each Spanish commercial and public service branch to the total electricity consumption (IDAE, 2018). While certain industrial branches suffered important decreases in their production levels in March and April 2020 (i.e. production of mineral products, steel industry), the essential ones kept about the same level of productivity (i.e. pharmaceutical preparations, manufacturing of soap and detergents, food and paper production, and, to a lesser extent, petroleum refining). In contrast, office and commer- cial buildings, schools, universities, restaurants and hotels, which represent more than $70 \%$ of the total electricity consumption, were obliged, in most cases, to close their facilities during the lockdown.

The reduction of power demand attributable to the manufacturing industry sector was then translated into a total reduction in industrial activity using the national energy balances reported in Eurostat (2020a) (Eq. 3):

$\operatorname{RF}_{\text {manuf_indu }}(d, c)=\frac{\operatorname{RF}_{\text {ene }_{\text {indu }}}(d, c) \times 0.25}{S_{\text {indu }}(c)}$,

where $\mathrm{RF}_{\text {manuf_indu }}(d, c)$ is the final reduction factor for the manufacturing industry sector for day $d$ and country $c$ [\%], $\mathrm{RF}_{\text {ene }}$ indu $(d, c)$ is the reduction factor for the total electricity demand for day $d$ and country $c$ estimated as described in Sect. 2.1 [\%], and $S_{\text {indu }}(c)$ is the share of final electricity consumed by the industrial sector in country $c[\%]$ (Eurostat, 2020a).

Figure $3 \mathrm{~b}$ shows the daily reduction factors computed for selected countries. The original positive values (i.e. increase in electricity consumption) obtained for the energy industry sector (Fig. 3b) were replaced by zeros for the calculations, as we consider it unlikely that average increases in manufacturing industrial emissions occurred during the lockdown. In general, the trends observed in all countries follow the same pattern as the ones presented for the energy industry. During the strictest period of the COVID-19 lockdown, computed reductions are between $-13 \%$ and $-10 \%$ for Italy, Spain, France and the UK, $-4 \%$ for Germany; and $-0.8 \%$ for Sweden.

\subsection{Road transport}

The emission reduction factors considered for the road transport sector are based on the Google COVID-19 Community Mobility Reports (Google LLC, 2020). The Google dataset reports daily movement trends over time by geography (country and region) across different categories of places 


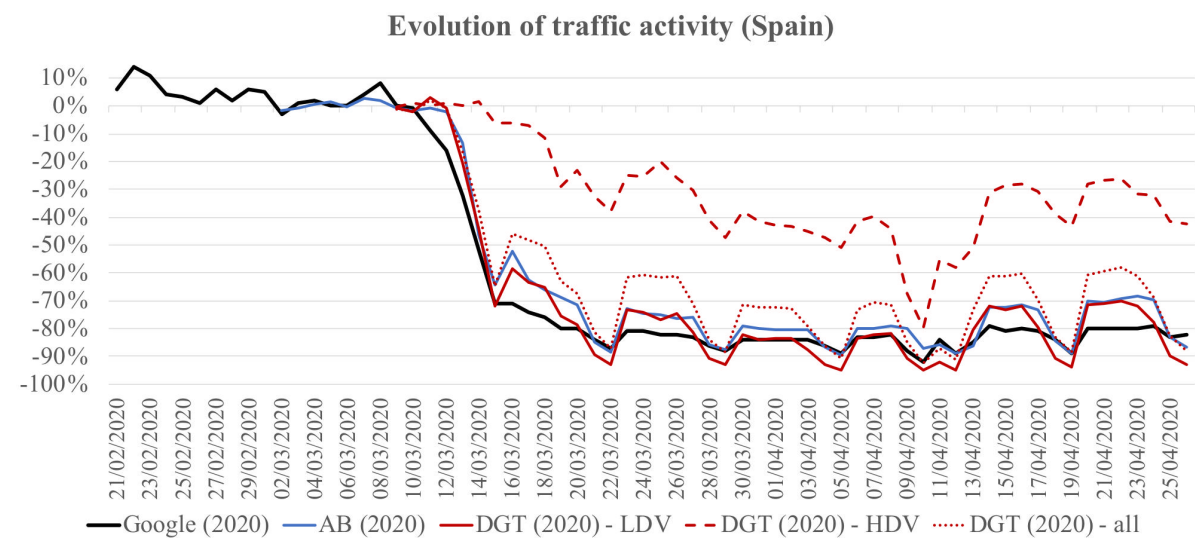

Figure 5. Comparison of traffic movement trends for Spain derived from Google reports (Google, 2020) and measured traffic counts in the city of Barcelona (ATM, personal communication) and the main Spanish interurban roads (DGT, 2020), the latter one being also distinguished by type of vehicle (i.e. light-duty vehicles, LDVs; heavy-duty vehicles, HDVs).

(i.e. groceries and pharmacies, parks, transit stations, retail and recreation, residential and workplaces) based on aggregated and anonymized sets of data from users who have turned on the "location history" setting for their Google account on their mobile devices. For the present study, we used the mobility trends reported for the transit station category, which includes places like public transport hubs such as subways, bus and train stations. The assumption behind this choice is that movement trends observed in public transport hotspots correlate with private transport trends. Reductions for each day are calculated by Google from a baseline taken as the median value, for the corresponding day of the week, over a 5-week period prior to the lockdowns (3 January to 6 February).

We evaluated the Google movement trends with actual measured traffic counts from the city of Barcelona (ATM, personal communication) and other major interurban roads in Spain (DGT, 2020), the latter discriminated by vehicle type (light and heavy duty) (Fig. 5). Note that for the Barcelona and DGT data, the information is available from 3 and 9 March onwards, respectively. In general terms, Google data reproduce the measurement-based trends obtained for the city of Barcelona $(\mathrm{BCN})$ and the Spanish interurban roads (DGT-all), with correlations of 0.96 and 0.92 , respectively. Overall, the average reductions reported by each of these three datasets are similar: $-74.6 \%$ (Google), $-69.1 \%$ (BCN) and $-63.62 \%$ (DGT-all). Using Google data at transit stations tends to slightly overestimate the reductions observed during the weekdays. However large discrepancies are shown when comparing the Google trend against the one reported by DGT for heavy-duty vehicles (DGT-heavy). The data from the DGT report an average reduction of heavyduty vehicles of only $-31 \%$ (more than 2 times lower than the one reported by Google), as these vehicles supported the delivery of essential goods and products (e.g. food, medical supplies). Nevertheless, we omitted the distinction between light- and heavy-duty vehicles when developing the reduction factors because CAMS-REG_AP/GHG traffic-related emissions are not discriminated by type of vehicle. Consequently, our factors for the traffic sector may overestimate the overall reduction of emissions, especially in areas with a higher share of heavy-duty vehicles, typically interurban roads. In order to quantify this uncertainty, we used the Spanish official EMEP road transport emissions (EMEP/CEIP, 2021) which, unlike CAMS-REG-AP, are reported by vehicle category, to quantify the impact of omitting the distinction between light- and heavy-duty vehicles when developing the reduction factors. We compared the $\mathrm{NO}_{x}$ average emission reductions obtained for the road transport sector during the strictest lockdown period (23 March to 26 April) when considering the DGT (2020) trends for heavy-duty vehicles instead of the Google movement trends. Results indicate a $-18 \%$ difference between the computed average reductions, i.e. $-528.5 \mathrm{t}$ when using Google trends for all vehicle categories and $-434.4 \mathrm{t}$ when considering specific heavy-duty vehicle trends (Fig. S4). This difference may vary across countries due to differences in (i) the impact of COVID-19 restriction on the activity of heavy-duty vehicles and (ii) the contribution of the heavy-duty vehicles to the overall traffic emissions. This approach may be improved in the future but was constrained in this study by data availability.

Figure $3 c$ shows the reduction factors proposed for selected countries. As in the case of the energy industry, the resulting trends are in line with the implementation and evolution of the national restrictions imposed in each country. The decrease in the traffic activity in Italy starts $2 \mathrm{~d}$ after the implementation of the localized lockdown and intensified once the national lockdown was imposed on 12 March, reaching reductions of about $-80 \%$. In the case of Spain and France, similar traffic reduction levels were reached just $3 \mathrm{~d}$ after the beginning of the corresponding national lockdowns. For the UK and Germany, the largest reductions are around $-70 \%$ 
and $-50 \%$, respectively. The lower reductions in Sweden (around $-40 \%$ ) are consistent with the lack of enforced mobility restrictions in this country at any point. In all cases, the activity started recovering during the last week of the period of study, coinciding with the relaxation of the mobility restrictions.

The list of countries included for this sector is summarized in Table 1. For countries without available data we constructed a set of average reduction factors considering all countries except Italy.

\subsection{Aviation}

We derived the reduction factors related to air traffic emissions during landing and take-off (LTO) cycles in airports from statistics provided by FlightRadar24 (FlighRadar24, 2020), which reports, every day, the total number of tracked operations per airport over the preceding $30 \mathrm{~d}$. For each country, we selected the largest airport to represent a national proxy. We computed country-specific daily flight operation trends using as a baseline value the average number of operations per airport from the previous year reported by Eurostat statistics (Eurostat, 2020b).

We started collecting the information from FlightRadar24 for all airports on 6 March, and the information from previous dates could not be retrieved as it is not archived. Therefore, our reduction factors have as an initial date 6 March in all cases, independently of the lockdown calendars. As shown in Fig. 3d for most countries the reductions in flight activity were starting to occur during those dates and therefore the trends presented are consistent. However, in some other countries such as Italy, reductions were already in a more advanced state (first day of reduction is $-15 \%$ ). We do not expect this lack of information to significantly affect the emission and air quality modelling results, as the contribution of this pollutant sector to total European emissions is very low, i.e. $1.1 \%$ and $0.14 \%$ to total $\mathrm{NO}_{x}$ and $\mathrm{PM}_{10}$ emissions, according to the last available EMEP official reported emission data (EMEP/CEIP, 2021). We expect to complement this information from alternative sources of data in a future release of the dataset. Regarding the obtained results, it is observed that in almost all countries, the reduction levels reached values of $-90 \%$ or more before the beginning of April. In contrast to road transport, there were no signs of recovery during the last week of April for this sector, as the movements between countries were still restricted at that time.

\section{Evaluating the reduction factors with air quality modelling}

We performed an emission and air quality modelling study as a first demonstration and evaluation of the applicability of the developed emission reduction factors. We used the Multi- scale Online Nonhydrostatic AtmospheRe CHemistry model (MONARCH) (see Sect. 3.1) and the High-Elective Resolution Modelling Emission System version 3 (HERMESv3) (Sect. 3.2) both developed at the Barcelona Supercomputing Center. The simulation period for the case study is from 20 January to 26 April 2020 . The study period covers 1 month of pre-COVID lockdown conditions (the first localized lockdowns in Europe began on 21 February in the region of Lombardy) and more than 2 months of lockdown conditions, including 5 weeks (23 March to 26 April) during which the most severe restrictions were already implemented in most (22) European countries. Therefore, the selected period of study allows analysis of the changes in concentrations between the lockdown period and before.

Three air quality simulations were run: (i) using the default CAMS-REG-APv3.1 emissions without considering any emission reduction, hereafter referred to as the baseline scenario; (ii) considering the traffic-related emission reduction factors only, hereafter referred to as the covid19_traffic scenario; and (iii) including the reduction factors from the traffic, energy and manufacturing industries and aviation sectors, hereafter referred to as the covid19_all scenario. The base year of the CAMS-REG-APv3.1 emissions used in the three scenarios is 2016, which was the most recent year available at the time of the study.

We also compared the model results against measurements of the European Environmental Agency (EEA) AQ eReporting (EEA, 2020) available through the Globally Harmonised Observational Surface Treatment (GHOST) project (Sect. 3.3). The model and evaluation work focus on $\mathrm{NO}_{2}$. Given that our main focus is the emission reductions and their evaluation, the inclusion of other relevant yet more model-dependent secondary pollutants such as $\mathrm{O}_{3}$ or $\mathrm{PM}_{2.5}$ is beyond the scope of this paper. The impact of the lockdown upon secondary pollutants, which are affected by more complex chemical interactions and source contributions, may be addressed in a follow-up multi-model study.

\subsection{MONARCH model}

MONARCH v1.0 (Pérez et al., 2011; Haustein et al., 2012; Jorba et al., 2012; Spada et al., 2013; Badia and Jorba, 2015; Badia et al., 2017) is a fully online integrated system for meso-scale to global-scale applications developed at the Barcelona Supercomputing Center (BSC). A flexible gasphase module combined with a hybrid sectional-bulk multicomponent mass-based aerosol module is implemented in the MONARCH model, which uses the Nonhydrostatic Multiscale Model on the B-grid (NMMB; Janjic and Gall, 2012) as the meteorological core driver. The Carbon Bond 2005 chemical mechanism (CB05; Yarwood et al., 2005) extended with toluene and chlorine chemistry is the gas-phase scheme used in MONARCH. The CB05 is well formulated for urban to remote tropospheric conditions and it considers 51 chemical species and solves 156 reactions. The rate con- 
stants were updated based on evaluations from Atkinson et al. (2004) and Sander et al. (2006). The photolysis scheme used is the Fast-J scheme (Wild et al., 2000). It is coupled with physics of each model layer (e.g. aerosols, clouds, absorbers as ozone) and it considers grid-scale clouds from the atmospheric driver. The Fast-J scheme has been updated with CB05 photolytic reactions. The quantum yields and cross section for the CB05 photolysis reactions have been revised and updated following the recommendations of Atkinson et al. (2004) and Sander et al. (2006). The aerosol module in MONARCH describes the life cycle of dust, sea salt, black carbon, organic matter (both primary and secondary), sulfate and nitrate aerosols. While a sectional approach is used for dust and sea salt, a bulk description of the other aerosol species is adopted. A simplified gas-aqueous-aerosol mechanism has been introduced in the module to account for the sulfur chemistry, the production of secondary nitrateand ammonium-containing aerosols is solved using the thermodynamic equilibrium model EQSAM, and a two-product scheme is used for the formation of secondary organic aerosols from biogenic gas-phase precursors. Meteorologydriven emissions are computed within MONARCH. Mineral dust emissions are calculated with an updated version of the Pérez et al. (2011) scheme, the sea salt aerosol emissions following Jaeglé et al. (2011) and biogenic gas-phase species using the MEGANv2.04 model (Guenther et al., 2006). The model provides operational regional mineral dust forecasts for the World Meteorological Organization (WMO; https://dust.aemet.es/, last access: January 2021) and participates in the WMO Sand and Dust Storm Warning Advisory and Assessment System for Northern Africa-Middle EastEurope (http://sds-was.aemet.es/, last access: January 2021). Since 2012, the system has contributed with global aerosol forecasts to the multi-model ensemble of the ICAP initiative (Xian et al., 2019), and since 2019, it has been a candidate model of the CAMS - Air Quality Regional Production (Marecal et al., 2015).

In this work, the model is configured for a regional domain covering Europe and part of northern Africa. The rotated latlong projection is used, with a regular horizontal grid spacing of $0.2^{\circ}$, and the top of the atmosphere is set at $50 \mathrm{hPa}$ using 48 vertical layers. Figure S1 displays the domain of study. Meteorological initial and boundary conditions were obtained from the ECMWF global model forecasts at $0.125^{\circ}$ and chemical boundary conditions from the CAMS global model forecasts at $0.4^{\circ}$ (Flemming et al., 2015). For an efficient execution of the modelling chain, the autosubmit workflow manager is used (Manubens-Gil et al., 2016).

\subsection{HERMESv3 emission system}

The original annual CAMS-REG-APv3.1 emission inventory was processed using the HERMESv3 system, an opensource, stand-alone multi-scale atmospheric emission modelling framework developed at the BSC that computes gaseous and aerosol emissions for use in atmospheric chemistry models (Guevara et al., 2019). The HERMESv3 system was used to remap the original CAMS-REG-AP data $\left(0.1^{\circ} \times 0.05^{\circ}\right)$ onto the MONARCH modelling domain and to derive hourly and speciated emissions. Aggregated annual emissions were broken down into hourly resolution using the emission temporal profiles reported by Denier van der Gon et al. (2011). The speciation of NMVOCs and PM emissions was performed using the split factors reported by TNO (Kuenen et al., 2014).

For the covid19_traffic and covid19_all scenarios, the estimated reduction factors (Fig. 3a-d) were combined with the original temporal profiles in order to model dynamic emission reductions for each sector and country. For each pollutant sector, we constructed a dataset of country-specific COVID-19 daily temporal profiles by combining the original temporal weight factors reported by Denier van der Gon et al. (2011) with the computed emission reduction factors, following Eq. (4):

DF_covid $19_{\mathrm{s}}(c, d)=\mathrm{DF}_{\mathrm{s}}(d) \times\left(1+\frac{\mathrm{RF}_{\mathrm{s}}(c, d)}{100}\right)$,

where $\operatorname{DF}_{\mathrm{s}}(d)$ represents the daily temporal factors for pollutant source $s$ and day of the year $d$ [0 to 366], and $\operatorname{RF}_{\mathrm{s}}(c, d)$ is the reduction factor computed for sector $s$, day of the year $d$ and country $c[\%]$. The $\mathrm{DF}_{\mathrm{S}}(d)$ weight factors were obtained by combining the original monthly (January to December) and weekly (Monday to Sunday) temporal profiles reported by Denier van der Gon et al. (2011). Figure 3e illustrates the COVID-19 daily temporal factors for the road transport sector in selected countries. The original daily profile for this sector, which is used in the baseline scenario, is also plotted for comparison purposes. In general, the temporal disaggregation of emissions would require the sum of the daily weight factors to be 366 (as in this case the year of study is a leap year). Nevertheless, and due to the application of the reduction factors, the sum of the COVID-19 daily factors do not add up to this number, which allows simulation of timeresolved emission reductions.

\subsection{Observational dataset}

The GHOST project is a BSC initiative dedicated to the harmonization of publicly available global surface observations (most notably air quality pollutants) and metadata, for the purpose of facilitating a greater quality of observationalmodel comparison in the atmospheric chemistry community (Bowdalo et al., 2020). Numerous networks are currently processed and contained under the umbrella of GHOST, including, among others, the EBAS and EEA networks. For each network, all relevant numerical and textual metadata (e.g. station classifications, measurement methodologies) are standardized and all data are passed through numerous quality control tests, giving detailed quality assurance (QA) flags. 
Daily average $\mathrm{NO}_{x}$ emissions $(23 / 03 / 2020-26 / 04 / 2020)$

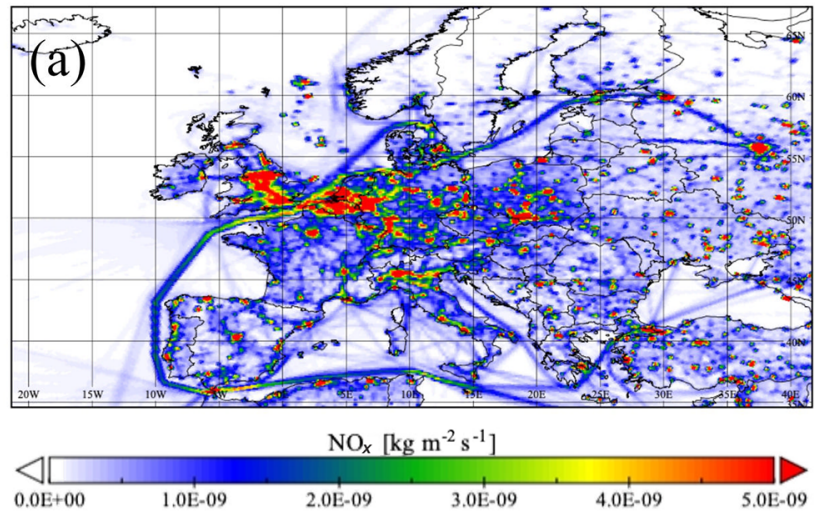

Daily average $\mathrm{NO}_{x}$ differences $(23 / 03 / 2020-26 / 04 / 2020)$
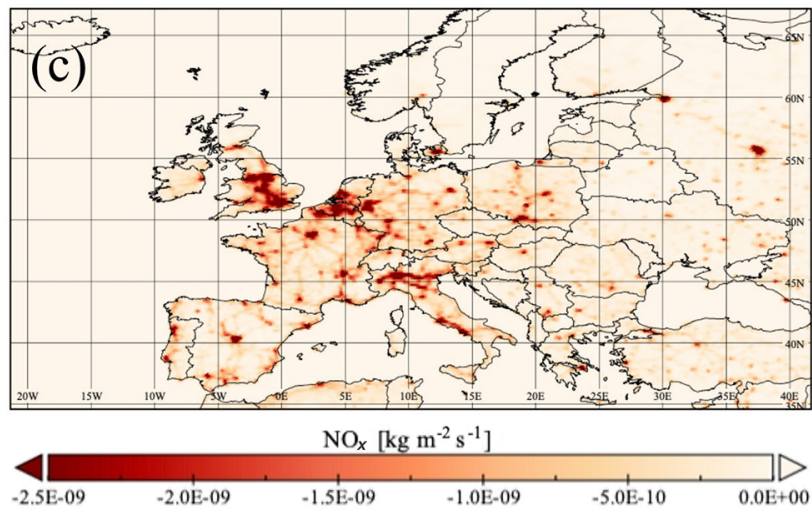

Daily average $\mathrm{NO}_{2}$ concentrations $(23 / 03 / 2020-26 / 04 / 2020)$

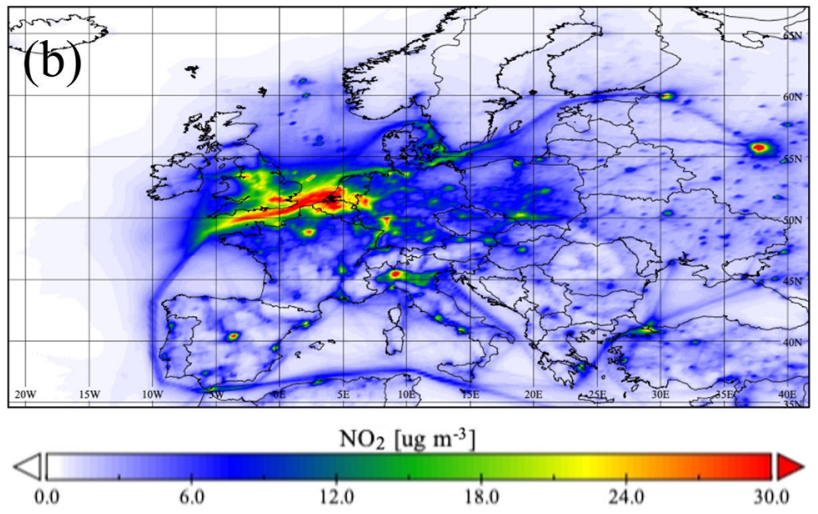

Daily average $\mathrm{NO}_{2}$ differences $(23 / 03 / 2020-26 / 04 / 2020)$

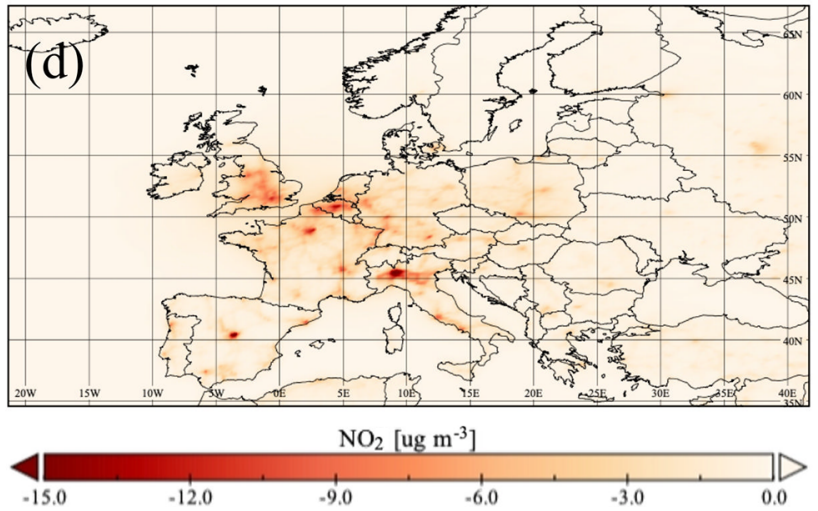

Figure 6. Maps of the daily average $\mathrm{NO}_{x}$ emissions $\left[\mathrm{kg} \mathrm{s}^{-1} \mathrm{~m}^{-2}\right]$ (a) and $\mathrm{NO}_{2}$ concentrations $\left[\mu \mathrm{g} \mathrm{m}^{-3}\right]$ (b) obtained for the baseline scenario (23 March to 26 April) and differences (c, d) when compared to the covid19_all scenario (i.e. covid19_all minus baseline). The spatial resolution of all maps is $0.2^{\circ} \times 0.2^{\circ}$.

In this work, we used the $\mathrm{NO}_{2}$ near-real-time EEA data. We selected rural and urban background stations located at selected countries (Italy, Spain, France, Germany, the UK and Sweden). In the case of urban background stations, we selected those located in Milan, Madrid, Paris, Berlin and London. For Sweden, and due to the low density of stations found in individual cities (e.g. Stockholm, one station), we decided to consider all urban background stations available countrywise (six). GHOST provides a wide range of harmonized metadata and quality assurance (QA) flags for all pollutant measurements. In this study, we took benefit of these flags to apply an exhaustive QA screening. More details on the QA flags used can be found in Appendix A. Note that for Italy, there is a data gap between 1 and 13 February at all stations. We nevertheless decided to keep this country in our evaluation study since it is one of the European countries most affected by the COVID-19 pandemic and the data gap does not affect the lockdown period. In the case of Sweden, only one rural background station was available for the entire country, which may reduce the representativity of the com- puted results. A detailed description of the stations is available in Table S1 in the Supplement and Fig. S5.

\section{Results and discussion}

Figure 6 shows maps of daily average $\mathrm{NO}_{x}$ emissions $\left[\mathrm{kg} \mathrm{s}^{-1} \mathrm{~m}^{-2}\right]$ and $\mathrm{NO}_{2}$ concentrations $\left[\mu \mathrm{g} \mathrm{m}^{-3}\right.$ ] obtained for the baseline scenario between 23 March and 26 April, as well as the differences with respect to the covid19_all scenario (i.e. covid19_all minus baseline). During this 5-week period most European countries were under severe national lockdown restrictions, which allows the illustration of the largest impacts upon emissions and air quality levels.

For both $\mathrm{NO}_{x}$ emissions and $\mathrm{NO}_{2}$ concentrations, the main reductions occurred in urban areas and the main interurban roads, especially within the most affected countries (i.e. Italy, Spain, France, the UK). The largest emission reductions are related to traffic (Sect. 4.1), which is the main contributor to urban $\mathrm{NO}_{2}$ levels, with approximately a $40 \%$ share on average (EEA, 2019). Below we discuss the results obtained 
from the modelling experiments in terms of daily changes in emissions (Sect. 4.1) and $\mathrm{NO}_{2}$ air quality concentrations (Sect. 4.2) during the study period.

\subsection{Emissions}

Figure $7 \mathrm{a}-\mathrm{d}$ shows the evolution of daily $\mathrm{NO}_{x}$, NMVOCs, $\mathrm{SO}_{x}$ and $\mathrm{PM}_{2.5}$ emissions during the entire period of study (20 January to 26 April) for EU-30 and for each of the three scenarios. The largest emission reductions occurred during the second and third weeks of March, when several European countries enforced national lockdown restrictions. After this period, there was a stabilization of the emission reductions until approximately 19 April. Thereafter, a slight recovery of the emission levels started to occur, which is consistent with the recovery of traffic activity shown in Fig. 3c. Overall, and when comparing the baseline and covid19_all scenarios, the reduction of total emissions is $-33 \%$ for $\mathrm{NO}_{x},-8 \%$ for NMVOCs, $-7 \%$ for $\mathrm{SO}_{x}$ and $-7 \%$ for $\mathrm{PM}_{2.5}$. The contribution of the traffic sector to total reductions is especially relevant for $\mathrm{NO}_{x}(90 \%)$, NMVOCs $(87 \%)$ and $\mathrm{PM}_{2.5}(82 \%)$ while for $\mathrm{SO}_{x}$ most of the total reduction can be attributed to the decreases in the energy and manufacturing industries (97\%), according to the results shown by the covid19_traffic scenario. Figure $7 \mathrm{e}$ and f illustrate the average and 5th and 95th percentiles (p05, p95) of the daily relative changes [\%] in the gridded $\mathrm{NO}_{x}$ emissions for Italy and Sweden. The results were computed considering all the grid cells within each of the countries. In Italy, the last 2 weeks of March and first 2 weeks of April show certain areas of the country reaching reductions up to $-75 \%$, whereas in other areas less affected by anthropogenic (and particularly road transport) emissions the reductions were significantly lower $(\sim-25 \%)$. In the case of Sweden, the reductions ranged between $-6 \%(\mathrm{p} 95)$ and $-36 \%$ (p05).

Figure 8 summarizes the average, minimum and maximum national daily emission changes [\%] obtained for $\mathrm{NO}_{x}$, NMVOCs, $\mathrm{SO}_{x}$ and $\mathrm{PM}_{2.5}$ between 23 March and 26 April for selected countries along with the average at the EU-30 level. Changes in emissions present strong variations from country to country and pollutant to pollutant. For $\mathrm{NO}_{x}$ and $\mathrm{SO}_{x}$, all countries except Germany and Sweden present stronger average reductions than the ones reported at the EU-30 level $(-33 \%$ and $-7 \%$, respectively), and Italy and France are the two countries with the largest reductions $\left(-50 \%\right.$ for $\mathrm{NO}_{x}$ and $-12 \%$ for $\left.\mathrm{SO}_{x}\right)$. For $\mathrm{NO}_{x}$, minimum and maximum daily emission reductions are in general relatively close to the average (e.g. Italy: avg $=-50 \%$, $\min =-47 \%$ and $\max =-56 \%$; Spain: avg $=-40 \%, \min =-43 \%$ and $\max =-46 \%$ ). In contrast, there are large differences among the average, minimum and maximum daily $\mathrm{SO}_{x}$ changes, especially in Germany (Sweden) where changes in emissions go from $0.6 \%(0.15 \%)$ to $-12 \%(-5 \%)$. The different behaviours observed for $\mathrm{NO}_{x}$ and $\mathrm{SO}_{x}$ are related to the different trends of the road trans- port and energy industry (Fig. 3a and c). The daily variability of the reduction factors for road transport is generally low; in the case of the energy industry large day-to-day variations are observed.

Despite having experienced one of the largest reductions in road transport activity (more than $-80 \%$ ), Spain was the country with the lowest decrease in total $\mathrm{PM}_{2.5}$ emissions $(-4.3 \%)$, and the second lowest in terms of NMVOCs $(-4.4 \%)$. Sweden shows a $\mathrm{PM}_{2.5}$ emission reduction of $-7.6 \%$, almost 2 times larger than Spain and very close to Italy $(-9.2 \%)$, despite its lower traffic activity decrease (less than $-40 \%)$. This is explained by the different contributions of the road transport sector contribution to total emissions in each country. Figure 9 shows the relationship between the reduction of traffic activity and contribution of the road transport sector to total emissions per country and pollutant. In the case of Sweden, road transport represents around $21.3 \%$ of total $\mathrm{PM}_{2.5}$ emissions, while in Spain the contribution is just $7.9 \%$. Similarly, in the case of NMVOCs emissions the contribution of road transport emissions is $15.9 \%$ in Italy and $8.9 \%$ in France, while in Spain it is only $4.3 \%$.

\subsection{Air quality}

Figure 10 shows the observed and modelled hourly $\mathrm{NO}_{2}$ concentrations between 20 January and 26 April at selected urban background sites in Italy (Milan), Spain (Madrid), France (Paris), the UK (London), Germany (Düsseldorf) and Sweden (all available sites). In the same way, the results at rural background stations are presented in Fig. 11. In both cases, the results are presented separately for each of the emission scenarios considered: baseline (in magenta), covid19_traffic (in green) and covid19_all (in blue). Statistical parameters computed on an hourly basis (i.e. mean bias, MB; root-mean-square error, RMSE; correlation coefficient, $r$ ) are presented for each emission scenario, country and station type for the pre-lockdown (20 January to 20 February) and most restrictive lockdown periods (23 March to 26 April) (Fig. 12). For the pre-lockdown period, the calculated statistics are equal for all scenarios, as no emission reductions are considered during that time. The computation of statistics during the pre-lockdown period allows quantification of the performance of the system under BAU conditions. We also compare the observed and simulated $\mathrm{NO}_{2}$ decline from the pre-lockdown to lockdown periods in each region, to quantify the accuracy of the estimated emission reduction factors (Fig. 13). Finally, Table 2 summarizes the absolute and relative changes of $\mathrm{NO}_{2}$ concentrations modelled at each station type and country between 23 March and 26 April.

The MONARCH model is capable of reproducing the urban background $\mathrm{NO}_{2}$ observations during the pre-lockdown period fairly well, particularly in London $\left(\mathrm{MB}=-0.25 \mu \mathrm{g} \mathrm{m}^{-3}, \mathrm{RMSE}=16 \mu \mathrm{g} \mathrm{m}^{-3}, r=0.74\right)$, Madrid $\left(\mathrm{MB}=-4 \mu \mathrm{g} \mathrm{m}^{-3}, \mathrm{RMSE}=19 \mu \mathrm{g} \mathrm{m}^{-3}, r=0.64\right)$ and Paris $\left(\mathrm{MB}=-7.7 \mu \mathrm{g} \mathrm{m}^{-3}, \quad \mathrm{RMSE}=13 \mu \mathrm{g} \mathrm{m}^{-3}, \quad r=\right.$ 
(a)

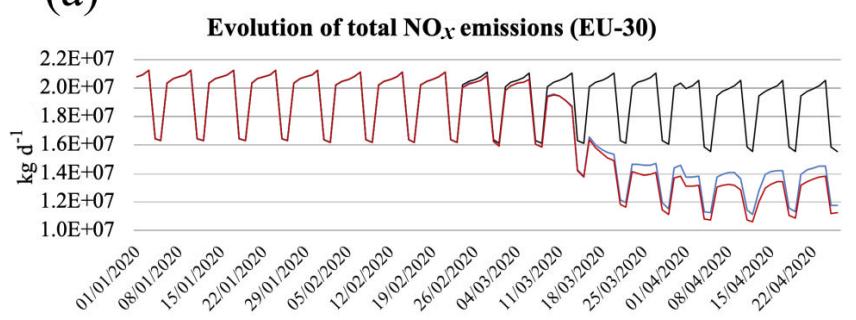

(c)

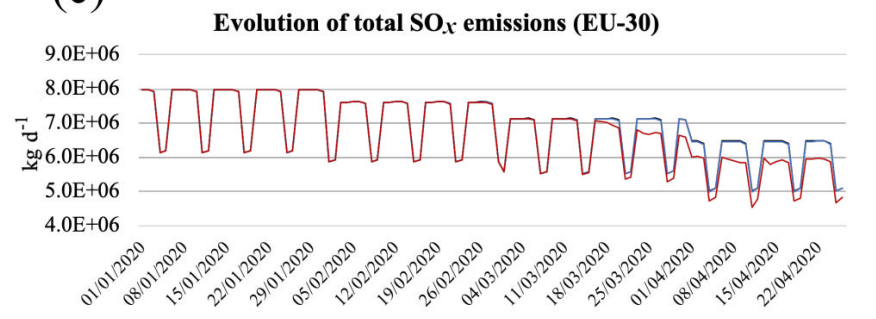

(b)

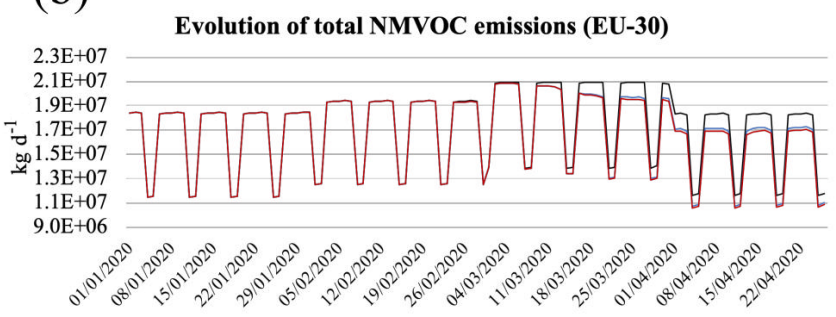

(d)

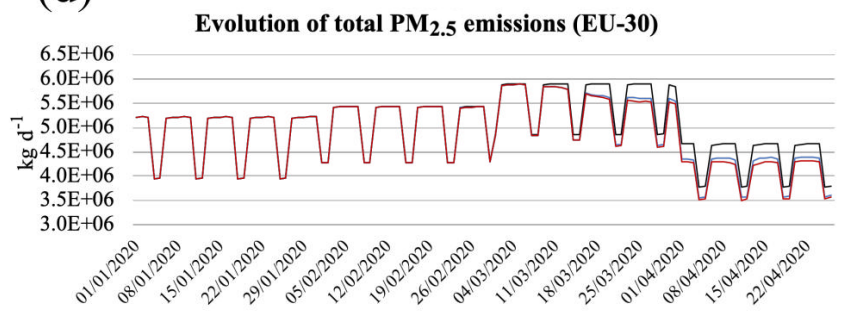

-baseline -covid19_traffic -covid19_all

(e)

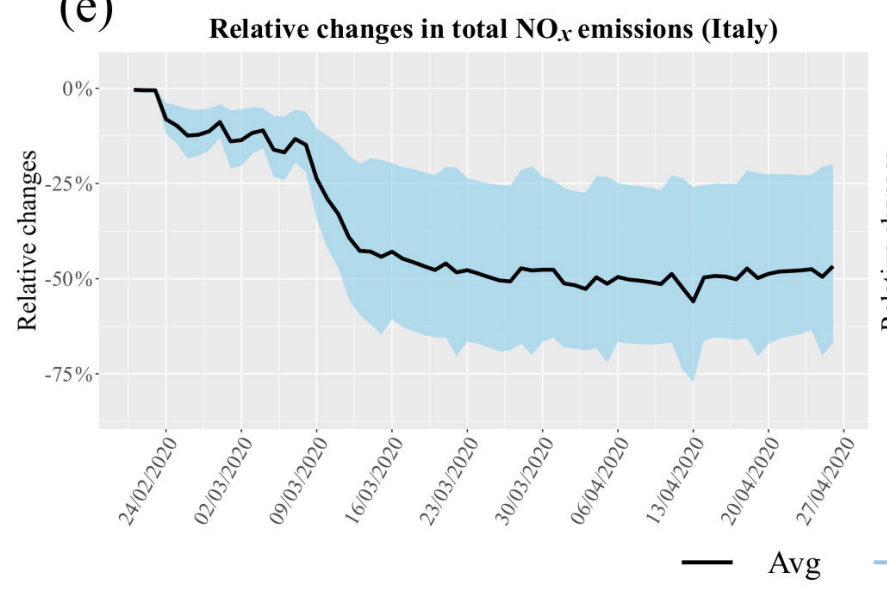

(f)

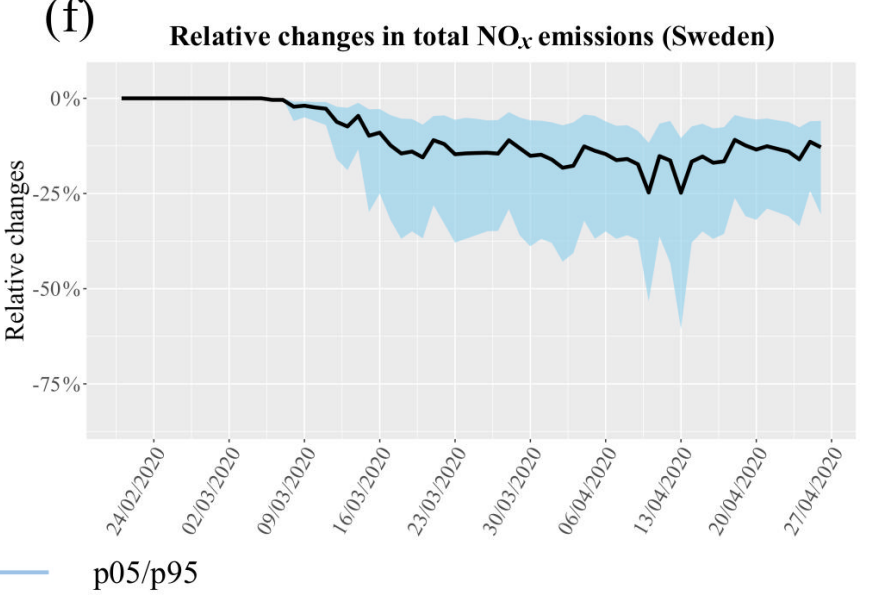

Figure 7. Evolution in daily $\mathrm{NO}_{x}(\mathbf{a}), \mathrm{NMVOCs}(\mathbf{b}), \mathrm{SO}_{x}(\mathbf{c})$ and $\mathrm{PM}_{2.5}(\mathbf{d})$ emissions $\left[\mathrm{kg} \mathrm{d}^{-1}\right.$ ] during the entire period of study (20 January to 26 April) for EU-30 and for each of the emission scenarios (baseline, covid19_traffic and covid19_all). Average (black) and 5th and 95th percentiles (p05/p95) (light blue shading) of the relative changes [\%] in gridded $\mathrm{NO}_{x}$ emissions in Italy (e) and Sweden (f) for the period 21 February to 26 April. The changes are computed considering the differences in total emissions reported by the covid19_all and baseline scenarios.

0.78). Milan is the location with the largest $\mathrm{MB}$ $\left(-14 \mu \mathrm{g} \mathrm{m}^{-3}\right)$ and RMSE $\left(22 \mu \mathrm{g} \mathrm{m}^{-3}\right)$. The relatively low performance in Milan may be related to the inability to reproduce the strong atmospheric stability conditions of the Po Valley region, a general problem for chemical transport models. After the implementation of the national lockdowns, a decrease in $\mathrm{NO}_{2}$ is simulated at all sites for both the covid19_traffic and covid19_all scenarios. Nevertheless, the decreasing rate strongly varies from one country to the next. In Madrid and Paris, $\mathrm{NO}_{2}$ concentrations drop abruptly just a few days after the beginning of the lockdown, while in Milan, Berlin and London the decreases occur at a slower pace. These results are consistent with the traffic activity re- duction trends computed for these countries (Fig. 3c). The statistics computed for the most restrictive lockdown period (23 March to 26 April) clearly reveal a general improvement of the model performance when the emission reductions are considered. As shown in Fig. 12, the calculated MB and RMSE values for the baseline scenario are significantly reduced when considering the covid19_traffic and covid19_all scenarios, especially in Madrid, Paris and London where overestimations of 9 to $14 \mu \mathrm{g} \mathrm{m}^{-3}$ are drastically reduced to 1 to $-1.5 \mu \mathrm{g} \mathrm{m}^{-3}$. In Berlin the performance of the model slightly decreases when considering the lockdown scenarios. Both the MB and RMSE of the baseline scenario remain lower in magnitude. This feature is attributed to a sig- 
(a) $\mathrm{NO}_{x}$ emission reductions $(23 / 03 / 2020-26 / 04 / 2020)$

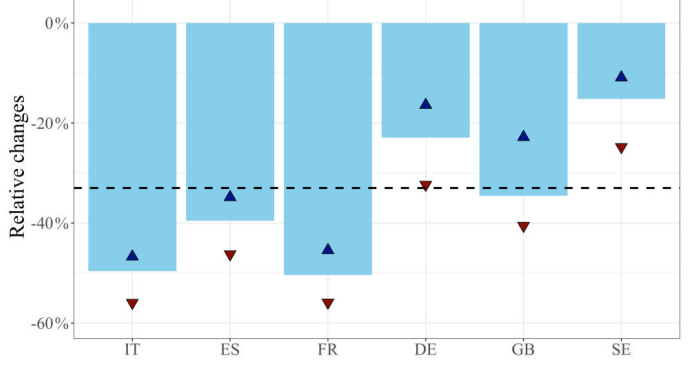

(c) $\mathrm{SO}_{x}$ emission reductions $(23 / 03 / 2020-26 / 04 / 2020)$

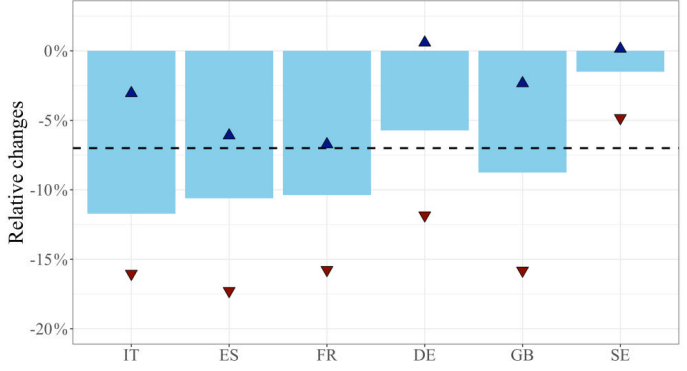

(b) NMVOC emission reductions (23/03/2020 - 26/04/2020)

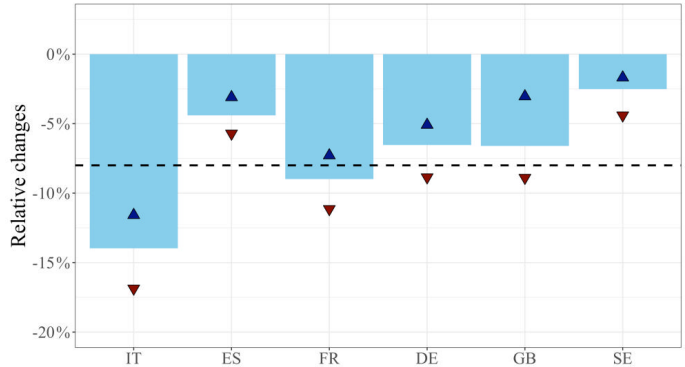

(d) $\mathrm{PM}_{2.5}$ emission reductions (23/03/2020 - 26/04/2020)

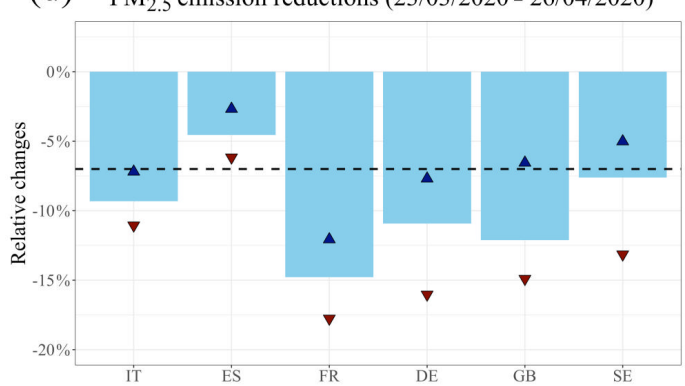

Avg

Min

Max - - EU-30

Figure 8. Average (Avg), maximum (Max) and minimum (Min) relative changes [\%] in total national $\mathrm{NO}_{x}(\mathbf{a}), \mathrm{NMVOCs}(\mathbf{b}), \mathrm{SO}_{x}(\mathbf{c})$ and $\mathrm{PM}_{2.5}$ (d) emissions for selected countries (IT, Italy; ES, Spain; FR, France; DE, Germany; GB, United Kingdom; SE, Sweden) between 23 March and 26 April. The dashed lines indicate the relative changes at the EU-30 level. The changes are computed considering the differences in total emissions reported by the covid19_all and baseline scenarios.

NOx

Traffic activity reduction $[\%]$

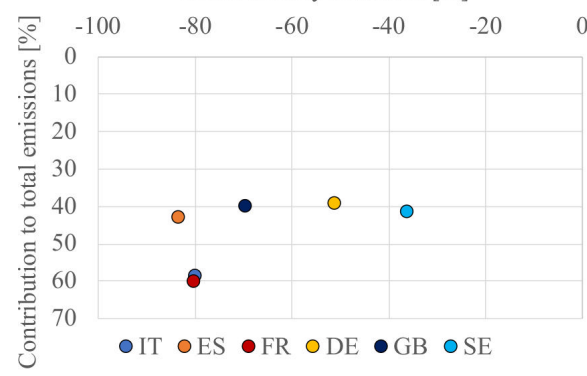

SO $x$

Traffic activity reduction [\%]

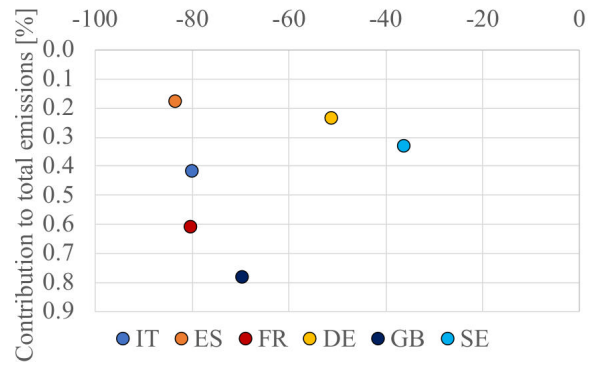

NMVOC

Traffic activity reduction [\%]

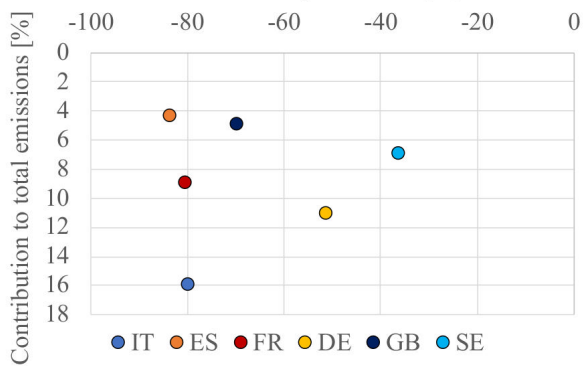

$\mathbf{P M}_{2.5}$

Traffic activity reduction [\%]

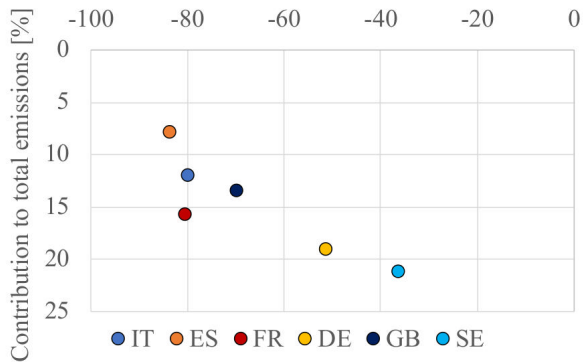

Figure 9. Relationship between the reduction of traffic activity (23 March to 26 April) and contribution of the road transport sector to total

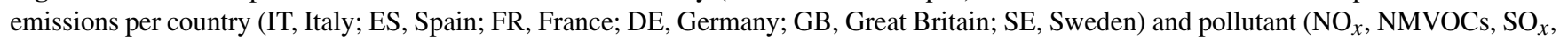
$\mathrm{PM}_{2.5}$ ). 
(a)

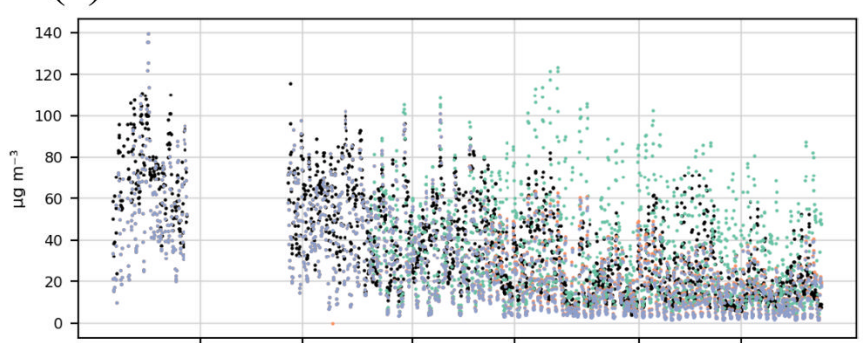

(c)

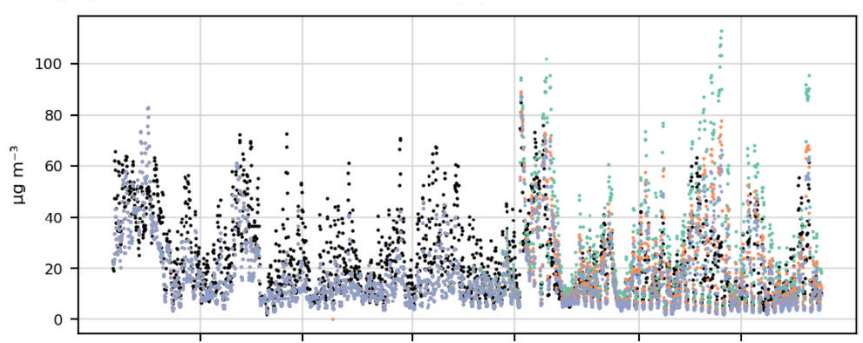

(e)

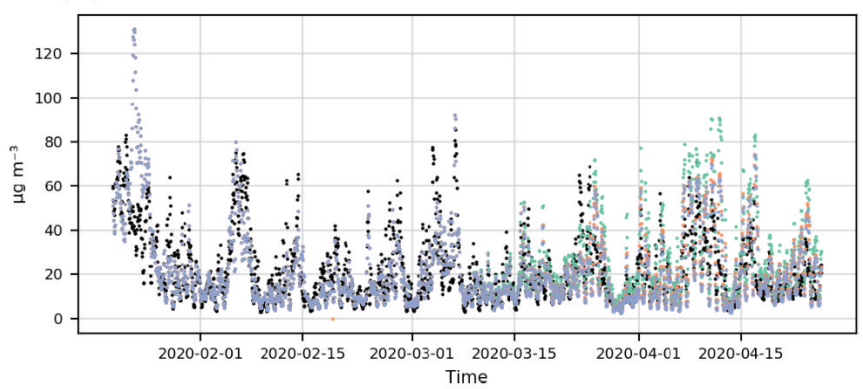

(b)

Madrid

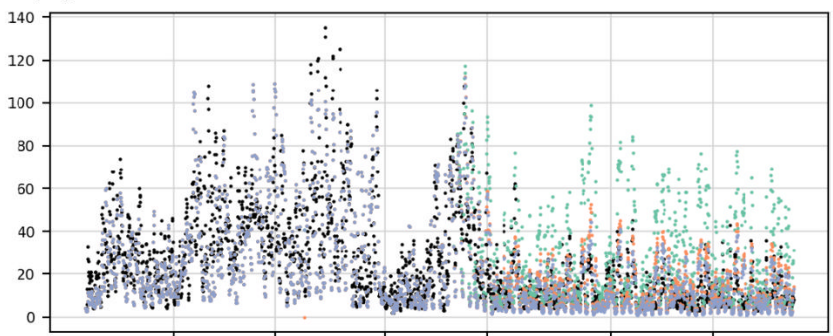

(d)

Berlin

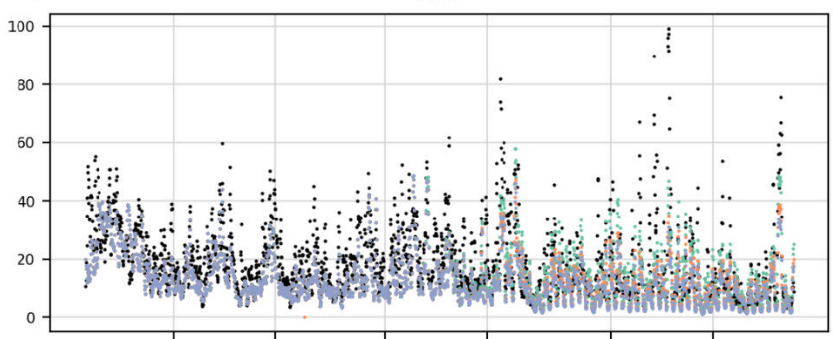

(f)

Sweden

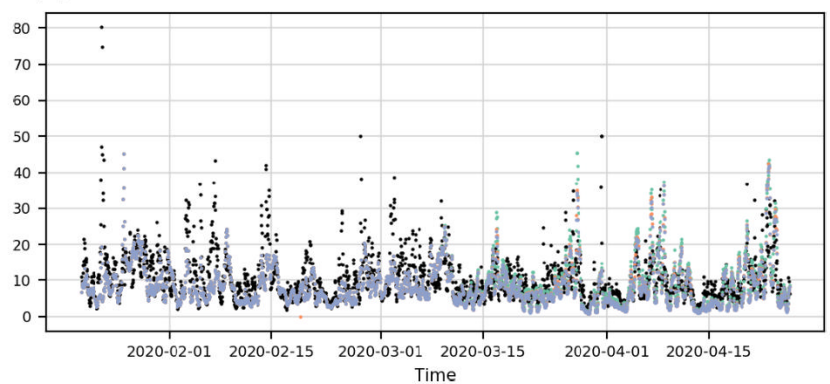

covid19_traffic

covid19_all

Figure 10. Observed (black) and modelled hourly $\mathrm{NO}_{2}$ concentrations $\left[\mu \mathrm{g} \mathrm{m}^{-3}\right.$ ] (20 January to 26 April) at selected urban background sites, including Milan (a), Madrid (b), Paris (c), Berlin (d), London (e) and Sweden (f, all available sites). Modelled results are presented separately for each of the emission scenarios considered: baseline (in magenta), covid19_traffic (in green) and covid19_all (in purple).

nificant increase in observed $\mathrm{NO}_{2}$ during the week of 7 April that neither the baseline nor the covid scenarios capture, due to either missed emission activity changes or errors in meteorology. In terms of correlation, no significant changes are observed when comparing the baseline and covid scenarios (for all cases except Milan values stay above 0.6). The simulated $\mathrm{NO}_{2}$ declines from the pre-lockdown to lockdown periods when considering the covid19_all scenario are fairly in line with the observed ones (Fig. 13a), although a general underestimation is shown (i.e. -7.3 and $-6.2 \mu \mathrm{g} \mathrm{m}^{-3}$ differences between modelled and observed declines in Italy and France, respectively). This underestimation could be related to the fact that we are currently not considering emission reductions from fuel combustion processes in commercial and institutional buildings, which were obliged to close during the lockdown period in almost all European countries. The computed absolute and relative decreases in $\mathrm{NO}_{2}$ urban background levels during the most restrictive lockdown period reveal that the differences between the covid19_traffic and covid19_all scenarios are generally low; i.e. the decrease in modelled $\mathrm{NO}_{2}$ concentrations is mainly driven by reduction of road traffic emissions. This is consistent with the large contribution of the traffic sector to total $\mathrm{NO}_{x}$ emission reductions as discussed in Sect. 4.1. According to the modelling results, the largest decreases in urban background $\mathrm{NO}_{2}$ levels during the lockdown period occur in Madrid $(-58 \%$ and $-51 \%$ for covid19_all and covid19_traffic, respectively) and Milan $(-56 \%$ and $-54 \%)$, followed by Paris $(-41 \%$ and $-32 \%)$, Berlin $(-30 \%$ and $-23 \%)$, London $(-28 \%$ and $-25 \%)$ and Sweden $(-11 \%$ and $-10 \%)$. Among these, 
(a)

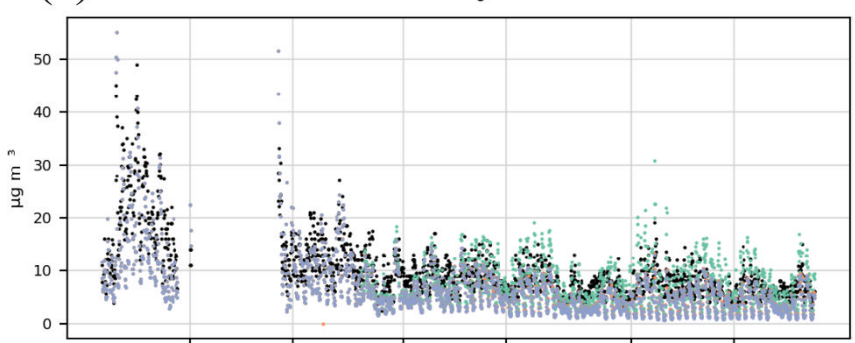

(c)

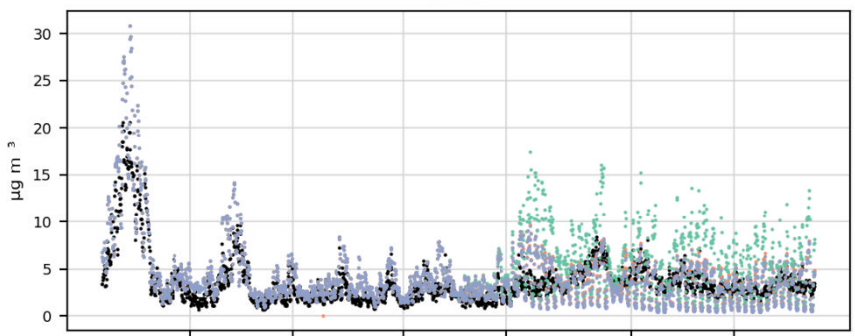

(e)

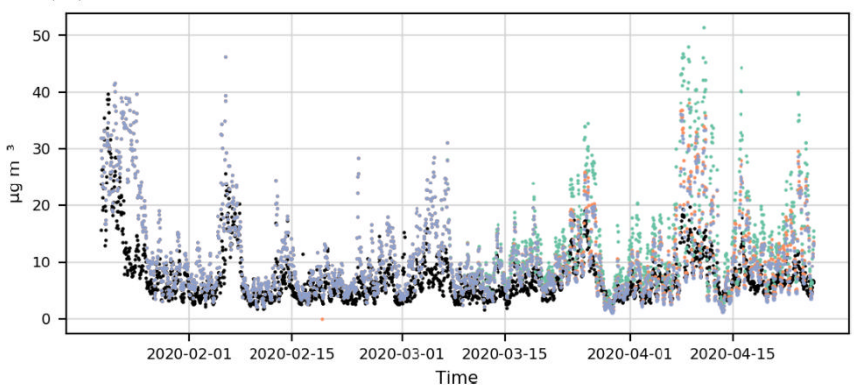

(b)

Spain

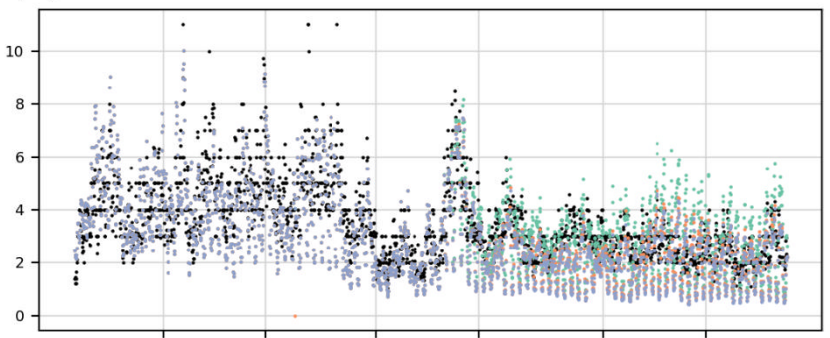

(d)

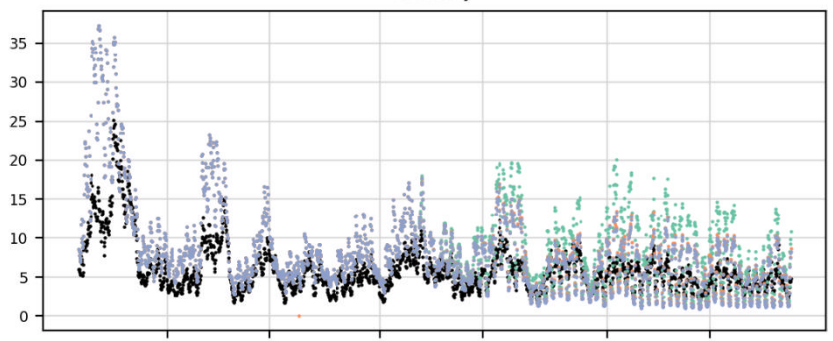

(f)

Sweden

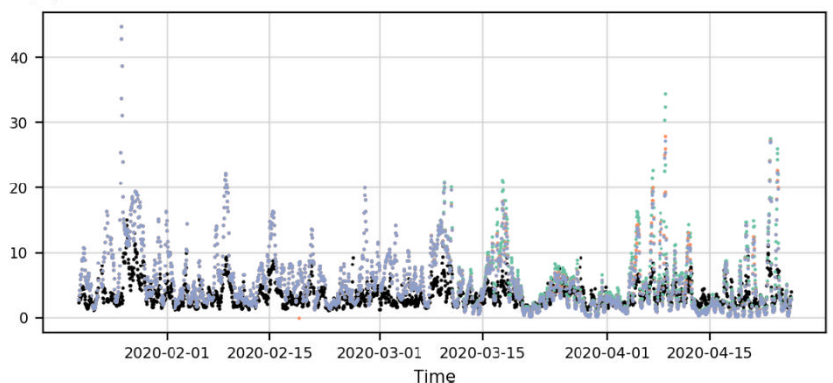

Time

observations

baseline

covid19_traffic

covid19_all

Figure 11. Observed (black) and modelled hourly $\mathrm{NO}_{2}$ concentrations [ $\mu \mathrm{g} \mathrm{m}^{-3}$ ] (20 January to 26 April) at selected rural background sites, including Italy (a), Spain (b), France (c), Germany (d), United Kingdom (e) and Sweden (f). Modelled results are presented separately for each of the emission scenarios considered: baseline (in magenta), covid19_traffic (in green) and covid19_all (in purple).

Paris and Berlin are the locations where non-traffic sources contribute more to total $\mathrm{NO}_{2}$ reductions (around $23 \%$ in both cases).

When it comes to rural background levels, prelockdown statistics also indicate a good capability of MONARCH in reproducing observed values, particularly in France $\left(\mathrm{MB}=1.5 \mu \mathrm{g} \mathrm{m}^{-3}, \mathrm{RMSE}=2.8 \mu \mathrm{g} \mathrm{m}^{-3}, r=0.93\right)$ and Spain $\left(\mathrm{MB}=-0.16 \mu \mathrm{g} \mathrm{m}^{-3}\right.$, RMSE $=1.3 \mu \mathrm{g} \mathrm{m}^{-3}, r=$ $0.52)$. A persistent overestimation is observed in Germany, the UK and Sweden (MB between 3.5 and $4.6 \mu \mathrm{g} \mathrm{m}^{-3}$ ), while in Italy the system tends to underestimate $(\mathrm{MB}=$ $-3.6 \mu \mathrm{g} \mathrm{m}^{-3}$ ). The overestimation in Germany, the UK and Sweden occurs mainly at night-time (not shown). Similar to what is observed at urban background sites, modelled and observed concentrations between 23 March and 26 April tend to be more in agreement when considering the emission reduction scenarios. The UK and Germany are the countries where the performance improves more, with $\mathrm{MB}$ values going from 7.5 and $2.3 \mu \mathrm{g} \mathrm{m}^{-3}$ (baseline) to 3.4 and $0.42 \mu \mathrm{g} \mathrm{m}^{-3}$ (covid19_traffic) and 3 and $0.29 \mu \mathrm{g} \mathrm{m}^{-3}$ (covid19_all). On the other hand, the improvement is not obvious in Italy, as the model shows a negative bias during the pre-lockdown period, and the lockdown scenarios constitute an important reduction of the modelled values. However, the trend is in agreement with results in Spain, France and Germany but with some additional underestimations. The modelled decline of $\mathrm{NO}_{2}$ concentrations from the pre-lockdown to lockdown periods presents a slight overestimation in all rural background regions except for Italy (Fig. 13b). The largest differences occur in Germany and France, where modelled 
(a)

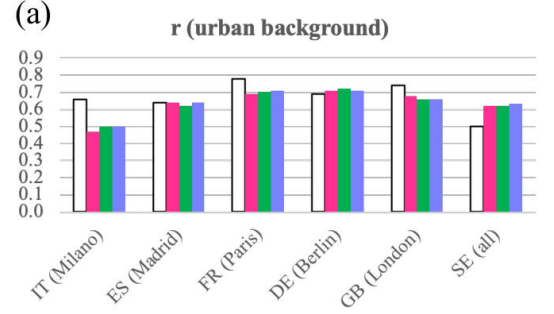

(d)

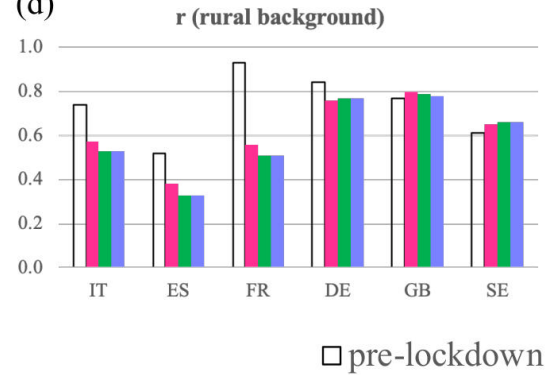

(b)

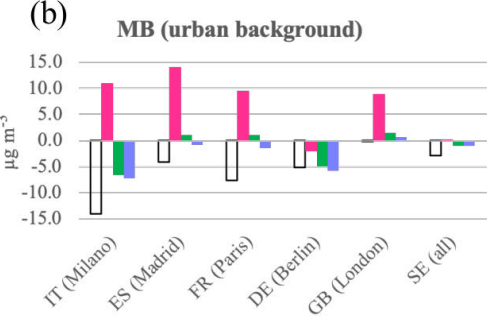

(e) $\quad$ MB (rural background)

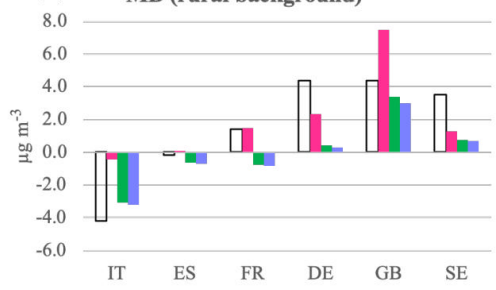

- baseline covid19 traffic (c) RMSE (urban background)

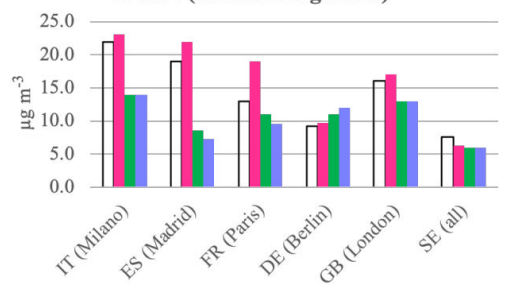

(f) RMSE (urban background)

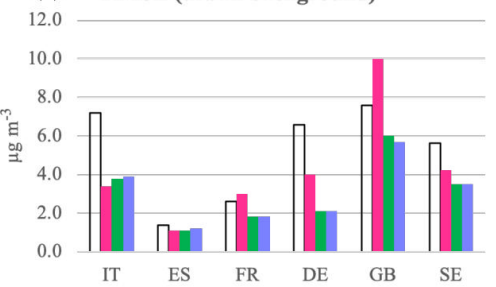

n covid19 all

Figure 12. Statistics calculated for $\mathrm{NO}_{2}$ on an hourly basis for the pre-lockdown period (20 January to 20 February) and the strictest lockdown period (23 March to 26 April) at urban (a-c) and rural (d-f) background stations for selected countries (cities). Statistics calculated for the most severe lockdown period are reported separately for each emission scenario (baseline, covid19_traffic and covid19_all), while for the pre-lockdown period this distinction is not made as the same emissions were used in all scenarios. The calculated statistics are mean bias $\left(\mathrm{MB}, \mu \mathrm{g} \mathrm{m}^{-3}\right)$, root-mean-square error (RMSE, $\mu \mathrm{g} \mathrm{m}^{-3}$ ) and correlation coefficient $(r)$.
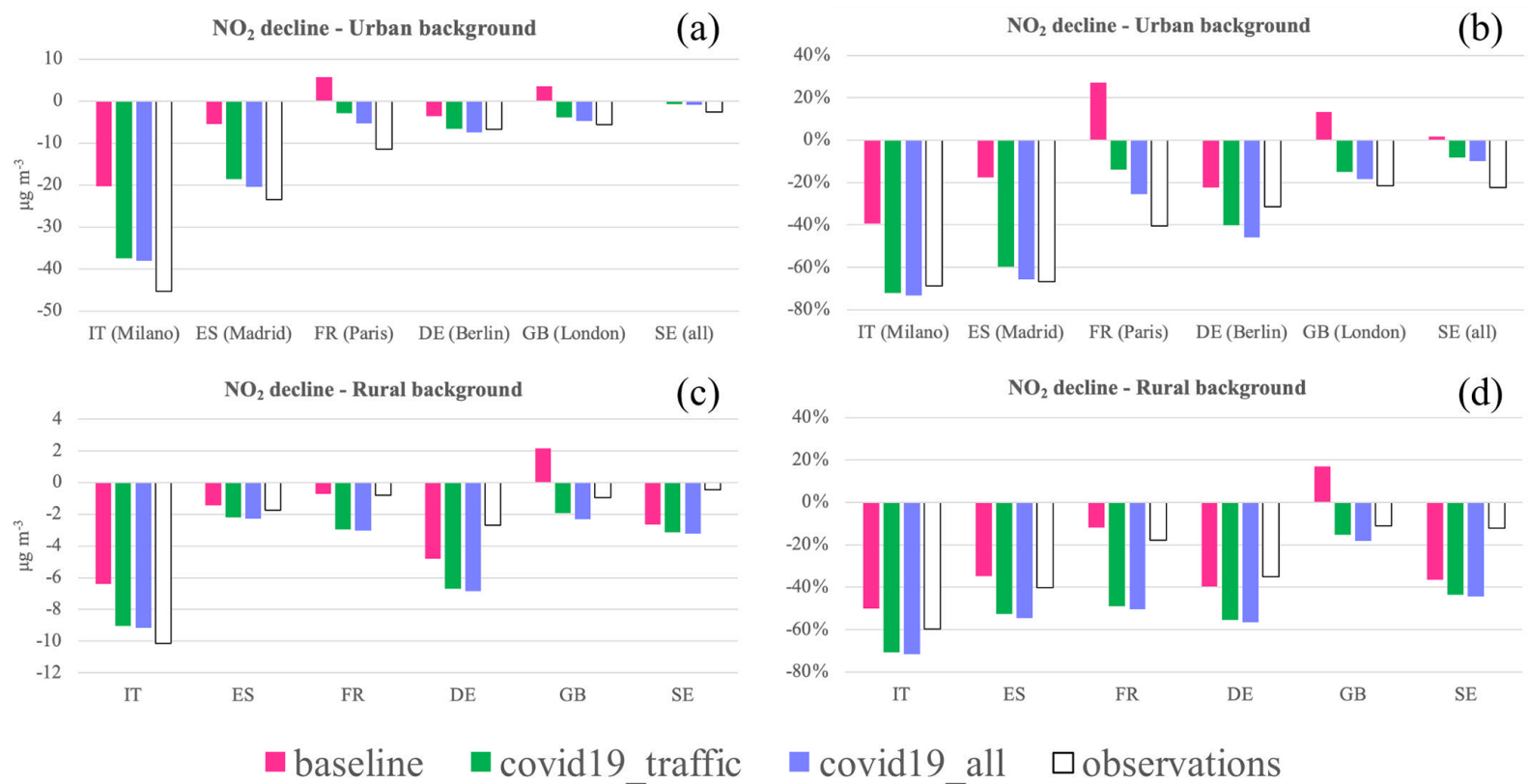

Figure 13. Absolute $\left[\mathrm{\mu g} \mathrm{m}^{-3}\right]$ and relative [\%] observed and modelled $\mathrm{NO}_{2}$ concentration declines from the pre-lockdown (20 January to 20 February) to lockdown (23 March to 26 April) periods at urban (a, b) and rural (c, d) background stations for selected countries (cities).

declines are 4.1 and $2.8 \mu \mathrm{g} \mathrm{m}^{-3}$ larger than the observed ones. Rural background levels can be determined by the combination of multiple emission sources, and therefore it is difficult to attribute these differences to a sole reason. Nevertheless, one plausible explanation for the obtained results could be the limitation of the Google mobility trends in representing the drop of emissions from heavy-duty vehicles, as discussed in Sect. 2.3. The rural background $\mathrm{NO}_{2}$ modelled concentrations in the two lockdown scenarios are substantially lower than in the baseline run. Nevertheless, the relative decreases modelled during the lockdown period are generally lower than in urban environments (Table 2). France $(-44 \%$ and 
$-42 \%$ for covid19_all and covid19_traffic, respectively) and Italy $(-43 \%$ and $-41 \%)$ are the countries that experience the largest decreases, followed by Spain, the UK and Germany (around $-30 \%$ and $-28 \%$ in all of them). In Sweden, relative reductions are almost equal to the ones obtained in urban background locations $(-12 \%$ and $-11 \%)$. Although no robust conclusions can be extrapolated as the results are based on only one rural station, the similar reductions obtained in both environments could be related to the soft restrictions implemented in this country. When comparing the covid19_all and covid19_traffic scenarios, only around $4 \%$ to $8 \%$ of the total reduction can be attributed to non-traffic sources.

\section{Conclusions}

This paper presents a dataset of day-, sector- and countrydependent emission reduction factors that allows quantification of the impact of the COVID-19 lockdown on European primary emissions and air quality levels. The reduction factors are provided for a period that goes from 21 February, when the first European localized lockdown was implemented in the region of Lombardy (Italy), to 26 April 2020, and for the four emission sectors presumably most affected by the mobility restrictions, i.e. road transport, energy industry, manufacturing industry and aviation. Our emission reduction factors are based on a wide range of information sources, including open-access and near-real-time measured activity data, proxy indicators, and other available reports. We also make use of machine learning techniques trained with meteorological data to estimate reductions in electricity consumption.

We combine the computed emission reduction factors with the Copernicus CAMS-REG-APv3.1 European gridded emission inventory to spatially and temporally quantify reductions in emissions from criteria pollutants. The resulting gridded and time-resolved emission reductions are used to perform an air quality modelling study to evaluate its capability of reproducing observed $\mathrm{NO}_{2}$ concentration changes in selected rural and urban background regions across Europe (Italy, Spain, France, Germany, the UK and Sweden). Three emission scenarios were considered: baseline scenario (no emission reductions applied), covid19_traffic scenario (consideration of emission reductions only from road transport) and covid19_all scenario (consideration of emission reductions from all four sectors).

The main findings and conclusions of this work are as follows.

- During the most severe lockdown period (23 March to 26 April), estimated emission reductions at the EU-30 level were $-33 \%$ for $\mathrm{NO}_{x},-8 \%$ for NMVOCs, $-7 \%$ for $\mathrm{SO}_{x}$ and $-7 \%$ for $\mathrm{PM}_{2.5}$, with road transport being the main contributor to total reductions in all cases (85\% or more) except for $\mathrm{SO}_{x}$, for which reductions were mainly driven by the energy and manufacturing industry sectors.

- Italy, France and Spain are the countries that experienced the major $\mathrm{NO}_{x}$ and $\mathrm{SO}_{x}$ emission reductions (up to $-50 \%$ and $-12 \%$, respectively), a result that is in line with the strong lockdown restrictions implemented by their corresponding governments. Conversely, Sweden shows reductions of only $-15 \%\left(\mathrm{NO}_{x}\right)$ and $-2.5 \%$ $\left(\mathrm{SO}_{x}\right)$ due to implementation of national recommendations instead of a state-enforced lockdown.

- Despite showing lower reductions of road transport activity, calculated reductions of total $\mathrm{PM}_{2.5}$ in Sweden are much larger $(-8 \%)$ than in Spain $(-4 \%)$. This is due to the variation in the contribution of the road transport sector to total emissions from country to country. While in Sweden road transport represents around $21.3 \%$ of total $\mathrm{PM}_{2.5}$ emissions, in Spain this contribution is of just $7.9 \%$. A similar outcome is obtained for NMVOCs when comparing traffic activity and total emission reductions in Spain and France.

- According to air quality modelling results, the larger decreases in urban background $\mathrm{NO}_{2}$ levels occurred in Madrid $(-58 \%)$ and Milan $(-56 \%)$. The calculated $\mathrm{NO}_{2}$ relative reductions at rural background areas are generally lower, with France $(-44 \%)$ and Italy $(-43 \%)$ being the countries that experience the largest decreases.

- In both urban and rural environments, the comparison between covid19_traffic and covid19_all results indicates that the road transport sector is on average responsible for $90 \%$ of the total $\mathrm{NO}_{2}$ reductions, with the largest and lowest contributions found in Milan (97\%) and Berlin (76\%), respectively.

- Overall, we found the performance of the modelled $\mathrm{NO}_{2}$ results to clearly improve when considering the emission reduction scenarios. Calculated MB values for the covid19_traffic and covid19_all scenarios are significantly lower than the ones estimated for the baseline scenario, especially in Madrid, Paris and London where overestimations of 9 to $14 \mu \mathrm{g} \mathrm{m}^{-3}$ are drastically reduced to 1 to $-1.5 \mu \mathrm{g} \mathrm{m}^{-3}$. On the other hand, the improvement is not so obvious at locations where the modelled results already display an important bias during the pre-lockdown period.

\subsection{Uncertainties}

In this work we present and evaluate a methodology not only to calculate time-resolved emission reductions associated with the COVID-19 lockdown, but also to adapt them for air quality modelling purposes, which may be relevant 
for the modelling community. There are, however, some limitations associated with the current version of the reduction factors dataset.

- First, and most importantly, emission changes in each sector were inferred from changes not observed directly in emissions but in general activity proxies such as electricity demand or mobility indicators. The use of such general indicators may lead to disregard of changes associated with specific processes or sources.

- Road transport. Comparisons against observed traffic counts showed that the Google movement trends are not representative of observed changes in heavy-duty vehicle activity and that their use may lead to a potential overestimation of the overall traffic activity reduction, especially on interurban roads, where the share of these vehicle categories is more important.

- Energy industry. The association between changes in electricity demand and emissions from power and heat plants neglects potential changes in the national power mixes. As recently presented by the International Energy Agency (IEA), certain countries have shifted their electricity production towards renewables following lockdown measures due to low operating costs and priority access to the grid through regulations, among others (IEA, 2020b). Omitting this aspect may be leading to an underestimation of the emission reductions for this sector and therefore will be revised in future versions of the dataset.

- Manufacturing industry. For this sector, the same reduction factors are assumed for all the industry branches. Yet, information reported by national industrial production indexes indicates that not all industrial sectors were affected in the same way by the lockdown restrictions. For instance, Spanish pharmaceutical, food and paper industries experienced almost no changes in their activity during April 2020 when compared to the previous year (between 0 and $-9 \%$ ), while industries related to the production of petroleum and mineral products showed moderate to significant decreases in April (between $-28 \%$ and $-43 \%$ ). For this month and country, the average reduction factor computed with the current methodology is $-12.5 \%$, which, despite falling within the range of the aforementioned reductions, is not representative of the changes reported for any of the specific industrial branches. In order to overcome this limitation, specific reduction factors should be developed for each industrial branch or groups of industrial branches presenting a similar behaviour.
- It is important to note that the specificity of the computed reduction factors also depends upon the degree of sectoral disaggregation used to report the original CAMS inventory. In the case of the manufacturing industry sector, all emissions are reported under a unique category, which hampers the consideration of industrial divisions. Similarly, traffic emissions are split by fuel category but not by vehicle category, which makes the use of different emission reduction factors as a function of the vehicle type difficult.

- Another important shortcoming is related to the spatial variability of the proposed reduction factors. In its current version, the reduction factors are countrydependent and therefore do not take into account potential variations within each country. This includes, for instance, the contrast between the large cut in road traffic to and from airports on the one hand and the traffic congestion of heavy-duty vehicles at the national borders captured by the Copernicus satellite images on the other (EU, 2020). This aspect will also be relevant when extending the time series of the dataset and including the period when governments started to soften lockdown measures. In some countries such as Spain this process was implemented heterogeneously across the different administration units.

\subsection{Future perspective}

Despite the aforementioned limitations, we believe that providing these timely emission modelling results will help with the understanding of air-quality-related aspects of the pandemic and also to better prepare in case of new waves or resurgences. As a matter of fact, this dataset supports a number of studies that are ongoing, in particular within CAMS and under the Global Atmosphere Watch Programme of the World Meteorological Organization (WMO/GAW). Future works will focus on amending the shortcomings mentioned above, particularly for the case of road transport emissions and the potential overestimation of the emissions drop from heavy-duty vehicles when using the Google mobility trends. Measured traffic counts from other countries will be collected in order to perform an intercomparison exercise against the Google movement trends and derive a set of European adjustment factors to consider when using the original Google dataset for computing changes in emissions from heavy-duty vehicles. Other works will be performed to extend the number of sectors considered, in particular the residential-commercial and shipping sectors, and cover the transition period towards the post-lockdown conditions. The investigation of the calculated emission reductions obtained when combining the reduction factors with the new CAMS emission temporal profiles (Guevara et al., 2020) will also be studied. New datasets and information sources will become available soon and therefore allow for an improvement 
in the representativeness of the current emission reductions. Moreover, the evaluation of the reduction factors in reproducing observed changes in other air pollutants such as $\mathrm{O}_{3}$ or $\mathrm{PM}_{2.5}$ will also be addressed in the future. We also expect to perform inter-comparisons of our modelled results against reductions associated with the COVID-19 lockdown derived from satellite-based observations following Barré et al. (2020). 
Appendix A: Quality assurance (QA) applied to $\mathrm{NO}_{2}$ observational dataset.

Using the information provided by GHOST (Globally Harmonised Observational Surface Treatment), we applied numerous QA screenings to the $\mathrm{NO}_{2}$ dataset, in order to remove missing measurements (flag 0 ), infinite values (flag 1), negative measurements (flag 2), zero measurements (flag 4), measurements associated with data quality flags given by the data provider which have been decreed by the GHOST project architects to suggest the measurements are associated with substantial uncertainty or bias (flag 6), measurements for which no valid data remain to average in the temporal window after screening by key QA flags (flag 8), measurements showing persistently recurring values (rolling 7 out of 9 data points; flag 10), concentrations greater than a scientifically feasible limit (above 5000 ppbv) (flag 12), measurements detected as distributional outliers using adjusted boxplot analysis (flag 13), measurements manually flagged as too extreme (flag 14), data with too coarse reported measurement resolution (above $1.0 \mathrm{ppbv}$ ) (flag 17), data with too coarse empirically derived measurement resolution (above $1.0 \mathrm{ppbv}$ ) (flag 18), measurements below the reported lower limit of detection (flag 22), measurements above the reported upper limit of detection (flag 25), measurements with inappropriate primary sampling for preparing $\mathrm{NO}_{2}$ for subsequent measurement (flag 40), measurements with inappropriate sample preparation for preparing $\mathrm{NO}_{2}$ for subsequent measurement (flag 41), and measurements with erroneous measurement methodology (flag 42). 
Data availability. The computed emission reduction factors per country, sector and day are provided in the Supplement.

Supplement. The supplement related to this article is available online at: https://doi.org/10.5194/acp-21-773-2021-supplement.

Author contributions. MG conceived and coordinated the development of the European emission reduction factors. MG and AS collected and analysed the input information required to compute the reduction factors. HP developed the machine learning algorithm for computing business-as-usual electricity demand during the COVID19 lockdown period. MG and OJ prepared the requirements for the modelling simulations. MG, CT and KS supervised the emission and air quality modelling simulations. DB performed the evaluation of the air quality modelling results. HDvdG and JK developed the CAMS-REG-AP emission inventory and have provided comments about the work. VHP has provided comments about the work and ensured liaison with wider activities in CAMS related to COVID-19 and air quality. OJ and CPGP helped conceive the European emission reduction factor dataset and supervised the work. MG prepared the manuscript with contributions from all co-authors.

Competing interests. The authors declare that they have no conflict of interest.

Acknowledgements. The research leading to these results has received funding from the Copernicus Atmosphere Monitoring Service (CAMS), which is implemented by the European Centre for Medium-Range Weather Forecasts (ECMWF) on behalf of the European Commission. We acknowledge support from the Ministerio de Ciencia, Innovación y Universidades (MICINN) as part of the BROWNING project RTI2018-099894-B-I00 and NUTRIENT project CGL2017-88911-R, the Agencia Estatal de Investigacion (AEI) as part of the VITALISE project (PID2019108086RA-I00/AEI/0.13039/501100011033), the AXA Research Fund, and the European Research Council (grant no. 773051, FRAGMENT). We also acknowledge PRACE and RES for awarding access to Marenostrum4 based in Spain at the Barcelona Supercomputing Center through the eFRAGMENT2 and AECT-2020-10007 projects. This project has also received funding from the European Union's Horizon 2020 research and innovation programme under the Marie Skłodowska-Curie grant agreement H2020-MSCACOFUND-2016-754433. Carlos Pérez García-Pando also acknowledges support received through the Ramón y Cajal programme (grant RYC-2015-18690) of the MICINN.

Financial support. This research has been supported by the Copernicus Atmosphere Monitoring Service (CAMS), which is implemented by the European Centre for Medium-Range Weather Forecasts (ECMWF) on behalf of the European Commission (grant no. CAMS_COP066), the Ministerio de Ciencia e Innovación (grant nos. RTI2018-099894-BI00, CGL2017-88911-R and RYC-201518690), the Agencia Estatal de la Investigación (grant no. PID2019108086-RA-I00/AEI/10.13039/501100011033), the AXA Research
Fund, the European Research Council (grant no. 773051, FRAGMENT) and Horizon 2020 (grant no. H2020-MSCA-COFUND2016-754433).

Review statement. This paper was edited by Qiang Zhang and reviewed by two anonymous referees.

\section{References}

Atkinson, R., Baulch, D. L., Cox, R. A., Crowley, J. N., Hampson, R. F., Hynes, R. G., Jenkin, M. E., Rossi, M. J., and Troe, J.: Evaluated kinetic and photochemical data for atmospheric chemistry: Volume $\mathrm{I}-$ gas phase reactions of $\mathrm{O}_{x}, \mathrm{HO}_{x}$, $\mathrm{NO}_{x}$ and $\mathrm{SO}_{x}$ species, Atmos. Chem. Phys., 4, 1461-1738, https://doi.org/10.5194/acp-4-1461-2004, 2004.

Badia, A. and Jorba, O.: Gas-phase evaluation of the online NMMB/BSC-CTM model over Europe for 2010 in the framework of the AQMEII-Phase2 project, Atmos. Environ., 115, 657669, https://doi.org/10.1016/j.atmosenv.2014.05.055, 2015.

Badia, A., Jorba, O., Voulgarakis, A., Dabdub, D., Pérez GarcíaPando, C., Hilboll, A., Gonçalves, M., and Janjic, Z.: Description and evaluation of the Multiscale Online Nonhydrostatic AtmospheRe CHemistry model (NMMB-MONARCH) version 1.0: gas-phase chemistry at global scale, Geosci. Model Dev., 10, 609-638, https://doi.org/10.5194/gmd-10-609-2017, 2017.

Barré, J., Petetin, H., Colette, A., Guevara, M., Peuch, V.-H., Rouil, L., Engelen, R., Inness, A., Flemming, J., Pérez García-Pando, C., Bowdalo, D., Meleux, F., Geels, C., Christensen, J. H., Gauss, M., Benedictow, A., Tsyro, S., Friese, E., Struzewska, J., Kaminski, J. W., Douros, J., Timmermans, R., Robertson, L., Adani, M., Jorba, O., Joly, M., and Kouznetsov, R.: Estimating lockdown induced European $\mathrm{NO}_{2}$ changes, Atmos. Chem. Phys. Discuss. [preprint], https://doi.org/10.5194/acp-2020-995, in review, 2020.

Bauwens, M., Compernolle, S., Stavrakou, T., Müller, J.-F., van Gent, J., Eskes, H., Levelt, P. F., van der A, R., Veefkind, J. P., Vlietinck, J., Yu, H., and Zehner, C.: Impact of coronavirus outbreak on $\mathrm{NO}_{2}$ pollution assessed using TROPOMI and OMI observations, Geophys. Res. Lett., e2020GL087978, https://doi.org/10.1029/2020GL087978, 2020.

Bowdalo, D., Vradi, A., Jorba, O., and Pérez García-Pando, C.: Globally Harmonised Observational Surface Treatment: Database of global surface gas observations, in preparation, 2020.

CIESIN: Center for International Earth Science Information Network CIESIN Columbia University C. Gridded Population of the World, Version 4 (GPWv4): Population Count. Palisades, NY: NASA Socioeconomic Data and Applications Center (SEDAC), https://doi.org/10.7927/H4X63JVC, 2016.

Collivignarelli, M. C., Abba, A., Bertanza, G., Pedrazzani, R., Ricciardi, P., and Miino, M. C.: Lockdown for CoViD-2019 in Milan: What are the effects on air quality?, Sci. Total Environ., 732, 139280, https://doi.org/10.1016/j.scitotenv.2020.139280, 2020.

C3S - Copernicus Climate Change Service: ERA5: Fifth generation of ECMWF atmospheric reanalyses of the global climate. Copernicus Climate Change Service Climate Data Store (CDS), 
available at: https://cds.climate.copernicus.eu/cdsapp $\{\#\} ! /$ home (last access: May 2020), 2017.

Denier van der Gon, H. A. C., Hendriks, C., Kuenen, J., Segers, A., and Visschedijk, A. J. H.: Description of current temporal emission patterns and sensitivity of predicted AQ for temporal emission patterns, EU FP7 MACC deliverable report D_D-EMIS_1.3, available at: https://atmosphere.copernicus.eu/ sites/default/files/2019-07/MACC_TNO_del_1_3_v2.pdf (last access: January 2021), 2011.

DGT - Directorate-General for Traffic: COVID-19 information, available at: http://www.dgt.es/es/covid-19/, last access: May 2020.

EEA: Air quality in Europe - 2019 report, EEA Report No. 10/2019, available at: https://www.eea.europa. eu/publications/air-quality-in-europe-2019 (last access: June 2020), 2019.

EEA: Air Quality e-Reporting Database, European Environment Agency, available at: http://www.eea.europa.eu/data-and-maps/ data/aqereporting-8, last access: May 2020.

EMEP/CEIP: Present state of emission data, available at: https://www.ceip.at/webdab-emission-database, last access: January 2021.

ENTSO-E: Transparency Platform, available at: https: //transparency.entsoe.eu/, last access: May 2020.

EU: EU Space response to Coronavirus, available at: https://www. copernicus.eu/es/coronavirus, last access: June 2020.

Eurostat: Energy balances, available at: https://ec.europa. eu/eurostat/web/energy/data/energy-balances (last access: May 2020), 2020a.

Eurostat: Airport traffic data by reporting airport and airlines, available at: https://ec.europa.eu/eurostat/web/products-datasets/ product?code=avia_tf_apal (last access: May 020), 2020b.

FGC UES: Russia's Federal Grid Company of Unified Energy System, UES/ECO performance indicators: Generation and consumption (hour), available at: http://www.so-cdu.ru/index.php? id=972\&tx_ms1cdu_pi1, last access: May 2020.

Flightradar24: Airport statistics, available at: https://www. flightradar24.com/data/airports, last access: May 2020.

Flemming, J., Huijnen, V., Arteta, J., Bechtold, P., Beljaars, A., Blechschmidt, A.-M., Diamantakis, M., Engelen, R. J., Gaudel, A., Inness, A., Jones, L., Josse, B., Katragkou, E., Marecal, V., Peuch, V.-H., Richter, A., Schultz, M. G., Stein, O., and Tsikerdekis, A.: Tropospheric chemistry in the Integrated Forecasting System of ECMWF, Geosci. Model Dev., 8, 975-1003, https://doi.org/10.5194/gmd-8-975-2015, 2015.

Google LLC: Google COVID-19 Community Mobility Reports, available at: https://www.google.com/covid19/mobility/, last access: May 2020.

Granier, C., Darras, S., Denier van der Gon, H. A. C., Doubalova, J., Elguindi, N., Galle, B., Gauss, M., Guevara, M., Jalkanen, J.-P., Kuenen, J., Liousse, C., Quack, B., Simpson, D., and Sindelarova, K.: The Copernicus Atmosphere Monitoring Service global and regional emissions (April 2019 version), Copernicus Atmosphere Monitoring Service (CAMS) report, 2019, Copernicus Atmosphere Monitoring Service (CAMS), Reading, UK, https://doi.org/10.24380/d0bn-kx16, 2019.

Guenther, A., Karl, T., Harley, P., Wiedinmyer, C., Palmer, P. I., and Geron, C.: Estimates of global terrestrial isoprene emissions using MEGAN (Model of Emissions of Gases and
Aerosols from Nature), Atmos. Chem. Phys., 6, 3181-3210, https://doi.org/10.5194/acp-6-3181-2006, 2006.

Guevara, M., Tena, C., Porquet, M., Jorba, O., and Pérez GarcíaPando, C.: HERMESv3, a stand-alone multi-scale atmospheric emission modelling framework - Part 1: global and regional module, Geosci. Model Dev., 12, 1885-1907, https://doi.org/10.5194/gmd-12-1885-2019, 2019.

Guevara, M., Jorba, O., Tena, C., Denier van der Gon, H., Kuenen, J., Elguindi-Solmon, N., Darras, S., Granier, C., and Pérez García-Pando, C.: CAMS-TEMPO: global and European emission temporal profile maps for atmospheric chemistry modelling, Earth Syst. Sci. Data Discuss. [preprint], https://doi.org/10.5194/essd-2020-175, in review, 2020.

Hale, T., Webster, S., Petherick, A., Phillips, T., and Kira, B.: Oxford COVID-19 Government Response Tracker, Blavatnik School of Government, available at: https://www.bsg.ox.ac.uk/ covidtracker, last access: May 2020.

Haustein, K., Pérez, C., Baldasano, J. M., Jorba, O., Basart, S., Miller, R. L., Janjic, Z., Black, T., Nickovic, S., Todd, M. C., Washington, R., Müller, D., Tesche, M., Weinzierl, B., Esselborn, M., and Schladitz, A.: Atmospheric dust modeling from meso to global scales with the online NMMB/BSC-Dust model - Part 2: Experimental campaigns in Northern Africa, Atmos. Chem. Phys., 12, 2933-2958, https://doi.org/10.5194/acp-122933-2012, 2012.

Hirth, L., Mühlenpfordt, J., and Bulkeley, M.: The ENTSO-E Transparency Platform - A review of Europe's most ambitious electricity data platform, Appl. Energy, 225, 1054-1067, https://doi.org/10.1016/j.apenergy.2018.04.048, 2018.

Huijnen, V., Pozzer, A., Arteta, J., Brasseur, G., Bouarar, I., Chabrillat, S., Christophe, Y., Doumbia, T., Flemming, J., Guth, J., Josse, B., Karydis, V. A., Marécal, V., and Pelletier, S.: Quantifying uncertainties due to chemistry modelling - evaluation of tropospheric composition simulations in the CAMS model (cycle 43R1), Geosci. Model Dev., 12, 1725-1752, https://doi.org/10.5194/gmd-12-1725-2019, 2019.

IDAE - Institute for Diversification and Saving of Energy: Detail of service sector consumption, available at: https://www.idae.es/en/ studies-reports-and-statistics (last access: May 2020), 2018.

IEA: Key energy statistics, Norway, available at: https://www.iea. org/countries/norway (last access: October 2020), 2020a.

IEA: Covid-19 impact on electricity, IEA, Paris, available at: https://www.iea.org/reports/covid-19-impact-on-electricity (last access: June 2020), 2020b.

INE Spanish Statistical Office: Industrial production, available at: https://www.ine.es/en/prensa/ipi_prensa_en.htm, last access: May 2020.

Jaeglé, L., Quinn, P. K., Bates, T. S., Alexander, B., and Lin, J.-T.: Global distribution of sea salt aerosols: new constraints from in situ and remote sensing observations, Atmos. Chem. Phys., 11, 3137-3157, https://doi.org/10.5194/acp-11-3137-2011, 2011.

Janjic, Z. and Gall, I.: Scientific documentation of the NCEP nonhydrostatic multiscale model on the $B$ grid (NMMB), Part 1: Dynamics, Tech. rep., NCAR/TN-489+STR, NCAR, University Corporation for Atmospheric Research, $75 \mathrm{pp}$., https://doi.org/10.5065/D6WH2MZX, 2012.

Jorba, O., Dabdub, D., Blaszczak-Boxe, C., Pérez, C., Janjic, Z., Baldasano, J. M., Spada, M., Badia, A., and Gonçalves, M.: Potential significance of photoexcited 
$\mathrm{NO}_{2}$ on global air quality with the NMMB/BSC chemical transport model, J. Geophys. Res.-Atmos., 117, D13301, https://doi.org/10.1029/2012JD017730, 2012.

Kuenen, J. J. P., Visschedijk, A. J. H., Jozwicka, M., and Denier van der Gon, H. A. C.: TNO-MACC_II emission inventory; a multi-year (2003-2009) consistent high-resolution European emission inventory for air quality modelling, Atmos. Chem. Phys., 14, 10963-10976, https://doi.org/10.5194/acp-14-109632014, 2014.

Le Quéré, C., Jackson, R. B., Jones, M. W., Smith, A. J. P., Abernethy, S., Andrew, R. M., De-Gol, A. J., Willis, D. R., Shan, Y., Canadell, J. G., Friedlingstein, P., Creutzig, F., and Peters, G. P.: Temporary reduction in daily global $\mathrm{CO} 2$ emissions during the COVID-19 forced confinement, Nat. Clim. Change, 10, 647653, https://doi.org/10.1038/s41558-020-0797-x, 2020.

Manubens-Gil, D., Vegas-Regidor, J., Prodhomme, C., Mula-Valls, O., and Doblas-Reyes, F. J.: Seamless management of ensemble climateprediction experiments on HPC platforms, in: 2016 IEEE International Conference on High Performance Computing \& Simulation (HPCS), Innsbruck, Austria, 895-900, https://doi.org/10.1109/HPCSim.2016.7568429, 2016.

Marécal, V., Peuch, V.-H., Andersson, C., Andersson, S., Arteta, J., Beekmann, M., Benedictow, A., Bergström, R., Bessagnet, B., Cansado, A., Chéroux, F., Colette, A., Coman, A., Curier, R. L., Denier van der Gon, H. A. C., Drouin, A., Elbern, H., Emili, E., Engelen, R. J., Eskes, H. J., Foret, G., Friese, E., Gauss, M., Giannaros, C., Guth, J., Joly, M., Jaumouillé, E., Josse, B., Kadygrov, N., Kaiser, J. W., Krajsek, K., Kuenen, J., Kumar, U., Liora, N., Lopez, E., Malherbe, L., Martinez, I., Melas, D., Meleux, F., Menut, L., Moinat, P., Morales, T., Parmentier, J., Piacentini, A., Plu, M., Poupkou, A., Queguiner, S., Robertson, L., Rouïl, L., Schaap, M., Segers, A., Sofiev, M., Tarasson, L., Thomas, M., Timmermans, R., Valdebenito, Á., van Velthoven, P., van Versendaal, R., Vira, J., and Ung, A.: A regional air quality forecasting system over Europe: the MACC-II daily ensemble production, Geosci. Model Dev., 8, 2777-2813, https://doi.org/10.5194/gmd-8-2777-2015, 2015.

Menut, L., Bessagnet, B., Siour, G., Mailler, S., Pennel, R., and Cholakian, A.: Impact of lockdown measures to combat Covid19 on air quality over western Europe, Sci. Total Environ., 741, 140426, https://doi.org/10.1016/j.scitotenv.2020.140426, 2020.

Pérez, C., Haustein, K., Janjic, Z., Jorba, O., Huneeus, N., Baldasano, J. M., Black, T., Basart, S., Nickovic, S., Miller, R. L., Perlwitz, J. P., Schulz, M., and Thomson, M.: Atmospheric dust modeling from meso to global scales with the online NMMB/BSC-Dust model - Part 1: Model description, annual simulations and evaluation, Atmos. Chem. Phys., 11, 1300113027, https://doi.org/10.5194/acp-11-13001-2011, 2011.

Petetin, H., Bowdalo, D., Soret, A., Guevara, M., Jorba, O., Serradell, K., and Pérez García-Pando, C.: Meteorologynormalized impact of the COVID-19 lockdown upon $\mathrm{NO}_{2}$ pollution in Spain, Atmos. Chem. Phys., 20, 11119-11141, https://doi.org/10.5194/acp-20-11119-2020, 2020.
Quayle, R. G. and Diaz, H. F.: Heating degree day data applied to residential heating energy consumption, J. Appl. Meteorol., 19, 241-246, https://doi.org/10.1175/15200450(1980)019<0241:HDDDAT>2.0.CO;2, 1980.

Rémy, S., Kipling, Z., Flemming, J., Boucher, O., Nabat, P., Michou, M., Bozzo, A., Ades, M., Huijnen, V., Benedetti, A., Engelen, R., Peuch, V.-H., and Morcrette, J.-J.: Description and evaluation of the tropospheric aerosol scheme in the European Centre for Medium-Range Weather Forecasts (ECMWF) Integrated Forecasting System (IFS-AER, cycle 45R1), Geosci. Model Dev., 12, 4627-4659, https://doi.org/10.5194/gmd-124627-2019, 2019.

RTE: Réseau de transport d'électricité: L'impact de la crise sanitaire (COVID-19) sur le fonctionnement du système électrique, available at: https://www.concerte.fr/system/files/concertation/ ImpactsdelacrisesanitaireCOVID-19surlesyst\%C3\%A8me\% C3\%A9lectrique.pdf, last access: October 2020.

Sander, S. P., Golden, D., Kurylo, M., Moortgat, G., Wine, P., Ravishankara, A., Kolb, C., Molina, M., Finlayson-Pitts, B., Huie, R., and Orkin, V. L.: Chemical kinetics and photochemical data for use in atmospheric studies, Evaluation no. 15, JPL Publication No. 06-02, Jet Propulsion Laboratory, Pasadena, available at: https://trs.jpl.nasa.gov/handle/2014/45510 (last access: January 2021), 2006.

Spada, M., Jorba, O., Pérez García-Pando, C., Janjic, Z., and Baldasano, J. M.: Modeling and evaluation of the global seasalt aerosol distribution: sensitivity to size-resolved and seasurface temperature dependent emission schemes, Atmos. Chem. Phys., 13, 11735-11755, https://doi.org/10.5194/acp-13-117352013, 2013.

Spinoni, J., Vogt, J., and Barbosa, P.: European degree-day climatologies and trends for the period 1951-2011, Int. J. Climatol., 35, 25-36, https://doi.org/10.1002/joc.3959, 2015.

Wild, O., Zhu, X., and Prather, M. J.: Fast-J: Accurate Simulation of In- and Below-Cloud Photolysis in Tropospheric Chemical Models, J. Atmos. Chem., 37, 245-282, https://doi.org/10.1023/A:1006415919030, 2000.

Xian, P., Reid, J. S., Hyer, E. J., Sampson, C. R., Rubin, J. I., Ades, M., Asencio, N., Basart, S., Benedetti, A., Bhattacharjee, P. S., Brooks, M. E., Colarco, P. R., da Silva, A. M., Eck, T. F., Guth, J., Jorba, O., Kouznetsov, R., Kipling, Z., Sofiev, M., Perez GarciaPando, C., Pradhan, Y., Tanaka, T., Wang, J., Westphal, D. L., Yumimoto, K. and Zhang, J.: Current state of the global operational aerosol multi-model ensemble: An update from the International Cooperative for Aerosol Prediction (ICAP), Q. J. Roy. Meteorol. Soc., 145, 176-209, https://doi.org/10.1002/qj.3497, 2019.

Yarwood, G., Rao, S., Yocke, M., and Whitten, G.: Updates to the Carbon Bond Chemical Mechanism: CB05, Final Report to the US EPA, RT-0400675, available at: http://www.camx.com/publ/ pdfs/CB05_Final_Report_120805.pdf (last access: April 2014), 2005. 